Article

\title{
Tough Polyelectrolyte Hydrogels with Antimicrobial Property via Incorporation of Natural Multivalent Phytic Acid
}

\author{
Hoang Linh Bui ${ }^{1}$ and Chun-Jen Huang ${ }^{1,2,3, *}$ \\ 1 Department of Biomedical Sciences and Engineering, National Central University, Taoyuan 32023, Taiwan; \\ hoanglinh2894@gmail.com \\ 2 Department of Chemical and Materials Engineering, National Central University, Taoyuan 32023, Taiwan \\ 3 R\&D Center for Membrane Technology, Chung Yuan Christian University, Taoyuan 32023, Taiwan \\ * Correspondence: cjhuang@ncu.edu.tw
}

Received: 26 September 2019; Accepted: 16 October 2019; Published: 21 October 2019

\begin{abstract}
Tough and antimicrobial dual-crosslinked poly((trimethylamino)ethyl methacrylate chloride)phytic acid hydrogel (pTMAEMA-PA) has been synthesized by adding a chemical crosslinker and docking a physical crosslinker of multivalent phytic acid into a cationic polyelectrolyte network. By increasing the loading concentration of PA, the tough hydrogel exhibits compressive stress of $>1 \mathrm{MPa}$, along with high elasticity and fatigue-resistant properties. The enhanced mechanical properties of pTMAEMA-PA stem from the multivalent ion effect of PA via the formation of ion bridges within polyelectrolytes. In addition, a comparative study for a series of pTMAEMA-counterion complexes was conducted to elaborate the relationship between swelling ratio and mechanical strength. The study also revealed secondary factors, such as ion valency, ion specificity and hydrogen bond formation, holding crucial roles in tuning mechanical properties of the polyelectrolyte hydrogel. Furthermore, in bacteria attachment and disk diffusion tests, pTMAEMA-PA exhibits superior fouling resistance and antibacterial capability. The results reflect the fact that PA enables chelating strongly with divalent metal ions, hence, disrupting the outer membrane of bacteria, as well as dysfunction of organelles, DNA and protein. Overall, the work demonstrated a novel strategy for preparation of tough polyelectrolyte with antibacterial capability via docking PA to open up the potential use of PA in medical application.
\end{abstract}

Keywords: polyelectrolyte; quaternary ammonium; phytic acid; multivalent ion effect; ion bridges; specific ion effect

\section{Introduction}

Hydrogels, a three-dimensional polymer network with high water content, has been extensively applied in biomedical applications, including tissue engineering scaffolds, tissue adhesives, drug delivery system, soft robotics, biosensors, and electronic components [1]. Recent studies have explored the potential of hydrogels in imitating human body tissue such as cartilage [2], skin [3], and muscle [4]. However, the conventional single network hydrogels with covalent crosslinks exhibited weak mechanical properties, which limits their potential uses of hydrogels in load-bearing applications [1]. The limitation stems from two major reasons: (1) ineffective energy dissipation within the polymeric network and (2) inhomogeneity distribution of polymer chain length [5,6]. To deal with these drawbacks, two outstanding approaches were introduced: nanocomposite hydrogels and interpenetrating polymer networks (IPN) [5]. Polymer chains within the nanocomposite hydrogel can be crosslinked with nanoclays through hydrogen bonds and coordinate bond to achieve structural homogeneity, thus, providing stretchable domains [6]. Whereas, in IPN, the fracture of the sacrificial first network provides effective energy dissipation and prevents catastrophic crack propagation under stress [5]. However, 
due to the nature of covalent bonds, damages caused by continuous stress results in permanent damage to IPN, leading to the loss of the mechanical properties over time [7]. To address the problem, many efforts have been made to incorporate or alter covalent crosslink with reversible physical crosslinker for fabricating tough hydrogels [1]. The physical crosslinkers can be temporally disrupted and recover when stress is removed, hence providing forced dissipation within the hydrated network. Owing to the dynamic behavior of physical crosslinking, hydrogels obtain extraordinary toughness along with maintaining their mechanical properties under repetitive impacts [7]. Notable physical-crosslinking strategies can include such as metal-coordination [8], hydrogen bonds [9], hydrophobic interaction [10], and ionic bonds [11].

Prevention of infection poses a key challenge for hydrogels to become an ideal biomaterial. While loading antibiotics into polymeric network is not an effective approach due to the wide-spread of antibiotic-resistant bacteria [12]. Alternatively, antimicrobial agents such as metal nanoparticles have been introduced and demonstrated a broad-spectrum bactericidal effect [13]. However, unrestrained release of metal nanoparticles from the nanoparticle-hydrogel composites may pose threats to human health and the environment [14]. Another alternative solution is to utilize quaternary ammonium-based (QA) polymers [15]. Polycationic polymers are able to disrupt the cytoplasmic membrane of bacteria in contact [16]. Furthermore, some studies have indicated the selective drug target of QA polymer for bacterial cells over eukaryotic cells $[17,18]$. Due to these attractive properties, Gan et al. have successfully interpenetrated quaternized chitosan into polydopamine (PDA)-derivatived polyampholyte via electrostatic interaction to enhance both antibacterial and mechanical properties of the hydrogels [19]. Nevertheless, contact-active strategy suffers from accumulation of dead bacteria on surfaces, which hinders the accessibility of antimicrobial properties and leads to the growth of bacteria and formation of biofilms [20]. In addition, our previous study has utilized zwitterionic polymer or polyethylene glycol to preventing the initial adhesion of bacteria on hydrogels [21-23]. Yet, a small amount of bacteria attachment can eventually generate biofilm formation on the antifouling surface. Thus far, antibacterial mechanism based on the "kill-and-release" strategy is proven to be the most promising approach [23]. The strategy combines both contact-active and passive-defense mechanisms into a coating surface. Hence, surface antibacterial properties of stimuli-responsive polymer can be switched reversibly under external stimulus (such as temperature [24], $\mathrm{pH}$ adjustment [25] and light [26]), aiming at prolonging antibacterial effect of the materials. In our previous study, we have proposed a novel "kill-and-release" strategy via docking counterions into quaternary ammonium-based poly((trimethylamino)ethyl methacrylate chloride) (pTMAEMA) brushes for reversible switching between bactericidal and bacterial-repellent functions [27]. As a result, the polyelectrolyte brushes demonstrated robust and regenerative cycles of killing and releasing bacteria by changing ion-pairing strength between positively charged surface and counterions. Nevertheless, in a highly water-absorbent hydrogel, it is problematic to employ the same approach into the polymeric network while avoiding mechanical damage to the hydrogels during operation. Therefore, it is important to employ a novel strategy to enhance antibacterial capability along with significantly improving the mechanical properties of the hydrogels.

Dating back to ancient times, plant extracts have been considered as one of the main bio-resources for drug discovery. With the surge of antibiotic-resistant bacteria recently, more and more attention has focused on the antimicrobial capability of herbal-originated substances, including tannin, quinones, and flavonoids [28]. These secondary metabolites have not only shown substantial antimicrobial capability against a wide range of pathogenic bacteria, fungi, and yeast via growth and protease inhibition and cell wall disruption, but also provide additional benefit for the body such as anti-inflammatory, antithrombotic and antioxidant [29-31]. Inspired by the compelling characteristics of a plant-based protocatechualdehyde in the formation of imide and coordinative bonds, Cheng's group has recently introduced a novel approach to fabricate a supramolecular multistimuli-responsive hydrogel with antibacterial capability [32]. Another plant derivative, phytic acid (PA) has been broadly applied in a variety of purposes, ranging from enhancing mechanical properties of materials $[33,34]$ to therapeutic uses such as anticancer drug [35]. Yet, to our knowledge, the fabrication of an antibacterial hydrogel incorporating with PA has not been explored. 
The ionotropic gelation technique, a process facilitating the crosslinking capability of multivalent ions, has been used in the pharmaceutical field [36]. Based on the same concept, Yang et al. has successfully utilized a series of multivalent cations $\left(\mathrm{Ca}^{2+}, \mathrm{Ba}^{2+}, \mathrm{Sr}^{2+}, \mathrm{Al}^{3+}\right.$ and $\left.\mathrm{Fe}^{3+}\right)$ to crosslink alginate/poly(acrylamide) hydrogel, thus, enhancing the mechanical properties of the polyanionic network [37]. As a result, the trivalent metal-ion/alginate hydrogel obtained high stiffness (Young's modulus achieved over $0.1 \mathrm{MPa})$ and high tensile strength $(>900 \mathrm{kPa})$. The electrostatic interaction of PTMAEMA with counterions has been reported in polyelectrolyte brushes [27,38-40]. Under the influence of ionic strength, the reversible switch from an extended state in low ionic strength to a coiled state in high ionic strength [41]. The robust ionic-responsive behavior of the strong polyelectrolyte has been successfully applied to modulate the surface properties of polymeric brushes, including wettability, friction, stiffness, lubricity, and protein adsorption, in a controllable fashion after docking with proper anions [27,40,42]. It is also worth mentioning that the ionic-responsive behavior of polyelectrolyte cannot be simply clarified based on the Debye-Hückel theory, which considers ions as point charges [43]. Instead, the difference in the nature of ions, such as ion size, solubility, and charge density and ion valency, should be considered for the overall comprehension of ion-ion interaction [37,44]. Beyond the ion-pairing strength, the use of ions to tune these properties of polyelectrolyte was proposed to be governed by several contributing factors, including ion specificity, hydrogen bonding and multivalent ion effect [42].

Based on previous findings [27,37,42], we proposed a novel dual-crosslinked pTMAEMA hydrogel obtaining both high fracture strength and antimicrobial capability by promoting non-covalent interaction between quaternary ammonium headgroups of pTMAEMA and multivalent-anionic PA. The compressive mechanical test and rheological test were first conducted to evaluate the effect of PA concentration on the mechanical strength and elasticity of pTMAEMA-PA. Next, the fatigue-resistant properties of pTMAEMA-PA were revealed in the compressive loading-unloading test. The ionic crosslinking mechanism of pTMAEMA-PA was evaluated by the stability test. In addition, a comparative study of swelling ratio and mechanical properties of pTMAEMA-anion complexes was further performed to elaborate other contributing factors in the enhancement of mechanical properties of PTMAEMA hydrogels. The anions in the study include $\mathrm{Cl}^{-}, \mathrm{SO}_{4}{ }^{2-}$, citrate $^{3-}$ and sodium hexametaphosphate ${ }^{6-}$ $\left(\mathrm{PP}^{6-}\right)$. The physical interactions between PA and pTMAEMA were confirmed by Fourier-transform infrared spectroscopy (FTIR) spectra analysis. For the antibacterial evaluation of pTMAEMA-PA, the typical pathogenic strains of bacteria including gram-negative Escherichia coli (E. coli) and gram-positive Staphylococcus epidermidis (S. epidermidis) were used in bacterial adhesion test and antibacterial diffusion test.

\section{Materials and Methods}

\subsection{Materials}

2-(Methacryloyloxy) ethyltrimethylammonium chloride solution (TMAEMA) were purchased from Alfa Aesar (Ward Hill, MA, USA). Sodium sulfate $\left(\mathrm{SO}_{4}{ }^{2-}\right)$ was purchased by Showa Chemical Industry (Tokyo, Japan). $N, N^{\prime}$-Methylenebis(acrylamide) (MBAA), sodium citrate tribasic dehydrate $\left(\right.$ Citrat $\left.^{3-}\right)$, sodium hexametaphosphate $\left(\mathrm{PP}^{6-}\right)$ were purchased from Sigma Aldrich (St. Louis, $\mathrm{MO}$, USA). Phytic acid (PA), 2-hydroxy-2-methylpropiophenone were purchased from Tokyo Chemical Industry Co., Ltd (Tokyo, Japan). LIVE/DEAD BacLight LIVE/DEAD BacLight was bought from Invitrogen (Carlsbad, CA, USA). Tryptic Soy broth, Luria-Bertani agar and broth were bought from Becton Dickinson (Franklin Lakes, NJ, USA) and Neogen (Lansing, MI, USA), respectively. Water used in these experiments was purified by a millipore water purification system with minimum resistivity of $18.0 \mathrm{M} \Omega \cdot \mathrm{m}$.

\subsection{Preparation of Polycationic Hydrogels}

The polycationic pTMAEMA hydrogels were synthesized by photo-initiated radical polymerization as demonstrated in Scheme 1. A mixed aqueous solution with the concentration of 2 M of TMAEMA, 
$0.5 \mathrm{~mol} \%$ crosslinker MBAA, $0.1 \mathrm{~mol} \%$ 2-hydroxy-2-methylpropiophenone relative to the total concentration of monomer and $0.5 \mathrm{M} \mathrm{NaCl}$ was carefully prepared into a reaction flask. The mixed solution was degassed with nitrogen for $1 \mathrm{~h}$. Next, $2 \mathrm{~mL}$ of the solution were added into one well of 24-well-plate culture plates, and the polymerization of the hydrogels were carried out under irradiating UV light (UV-LED, Brightek, Taoyuan, Taiwan) with the intensity of $100 \mathrm{~mW} / \mathrm{cm}^{2}$ for $30 \mathrm{~min}$. After the polymerization, the as-prepared samples were immersed into DI water for 1 day, and the water was changed three times during the time period to remove excessive residues. The final hydrogels were dried in oven and then immersed in different electrolyte solutions for the evaluation of swelling ratio and the mechanical properties of the gels. Hydrogels samples after docking couterions $\left(\mathrm{Cl}^{-}, \mathrm{SO}_{4}{ }^{2-}\right.$, Citrate $^{3-}, \mathrm{PP}^{6-}$ and $\mathrm{PA}$ ) were generally termed as pTMAEMA-anion-Co, where anion is the counterion in electrolyte solution and $\mathrm{Co}$ is the loading concentration of counterions in $\mathrm{mol} / \mathrm{L}$.

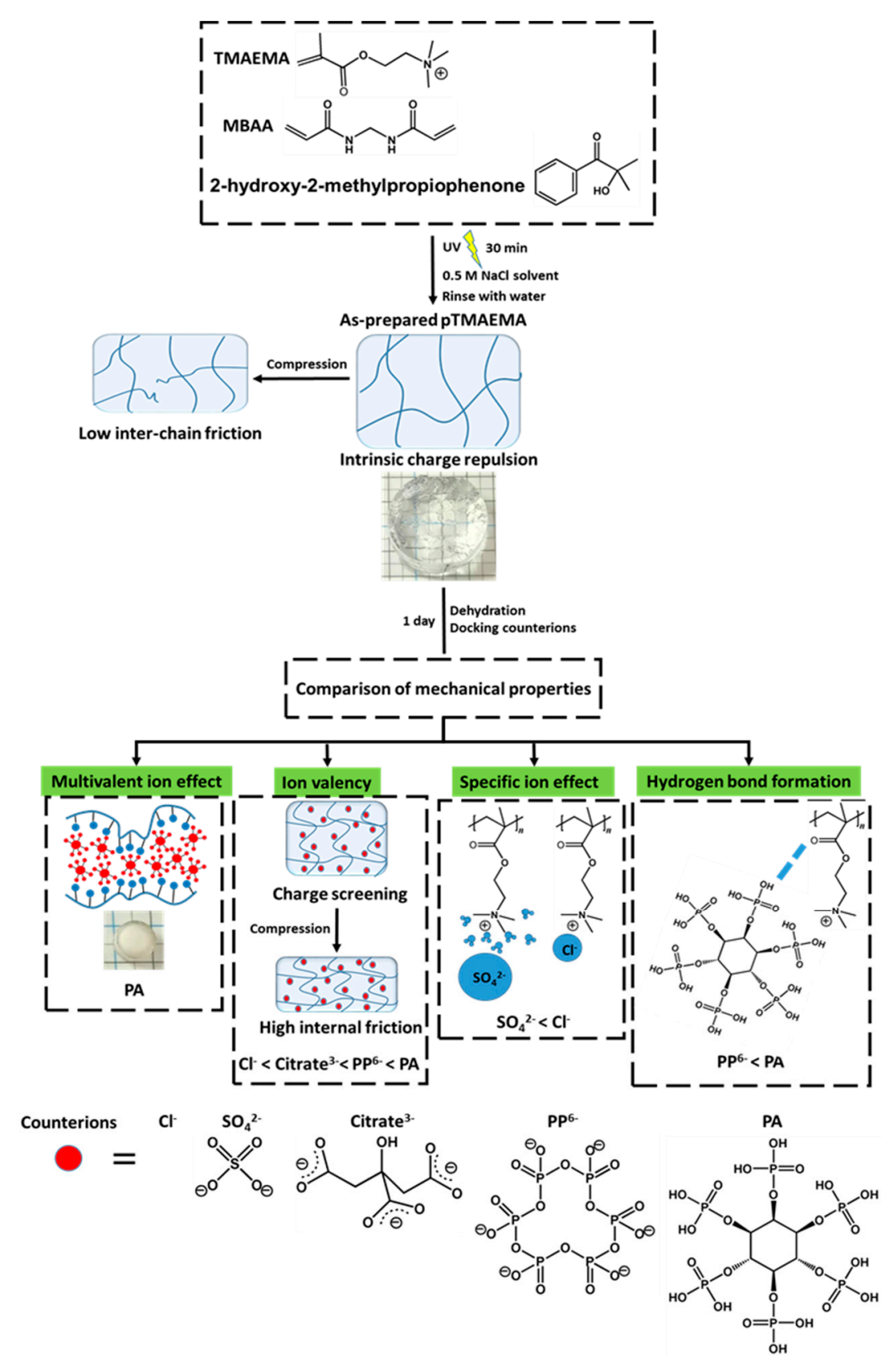

Scheme 1. Two-step method in synthesize poly((trimethylamino)ethyl methacrylate chloride) docking with counterions (pTMAEMA-anion) and the mechanisms underline the enhanced mechanical properties of pTMAEMA hydrogels. 


\subsection{Compressive Mechanical Test}

Compressive mechanical properties of hydrogels samples were measured with a universal testing machine (QC-513M1F, Cometech, Taichung, Taiwan). To obtain the compressive strain-stress curves, cylindrical hydrated hydrogels of pTMAEMA-anion were compressed to their maximum strain between two parallel plates with a deformation rate of $0.5 \mathrm{~mm} / \mathrm{min}$ at room temperature. Engineering fracture stress $\sigma_{\mathrm{f}}$, fracture strain $\epsilon_{\mathrm{f}}$ were recorded. Young's modulus $(E)$ was calculated from the initial slope of the compressive stress-strain curve with strain from $5 \%$ to $10 \%$, while maximum compressive modulus $\left(E_{\max }\right)$ was obtained from the slope within the range of $5 \%$ strain before fracture. The compressive toughness $\left(T_{\mathfrak{C}}\right)$ was calculated as deformation energy under uniaxial compression per unit volume of the samples.

For the compressive loading-unloading test, pTMAEMA-PA-1 hydrogel was first compressed to $60 \%$ and $70 \%$ deformation at the rate of $6 \mathrm{~mm} / \mathrm{min}$ and then unloaded at the same deformation rate to complete one loading-unloading cycle. The successive cycle was performed 10 times with the same hydrogel. Hysteresis energy in each cycle was estimated by recording as the area within the loading-unloading curves of 10 cycles.

\subsection{Rheological Test}

Frequency Sweep test was performed with a rheometer DHR-2 (TA instrument, New Castle, DE, USA) to obtain the storage modulus $\left(G^{\prime}\right)$, loss modulus $\left(G^{\prime \prime}\right)$ and loss factor $(\tan \delta)$ of pTMAEMA-PA. The frequency sweeps were conducted with an angular frequency range of $0.1-100 \mathrm{rad} / \mathrm{s}$ and a strain of $1 \%$ at room temperature.

\subsection{Stability Test}

To investigate the counterion exchange effect on the hydrogel, pTMAEMA-PA-1 prepared as described above were immersed in excess volume of a $\mathrm{NaCl}$ solution at different concentrations for 1 day to reach equilibrium. The change in volume and Young's modulus of the hydrogels under the concentration of saline solution were analyzed to assess the stability of ionic bonds within pTMAEMA hydrogels. The volume of pTMAEMA-PA was measured before and after immersing in $\mathrm{NaCl}$ solution by using a vernier caliper. The volume change ( $\%$ to original) was calculated as the ratio of the volume of pTMAEMA-PA- 1 after ion exchange process to their original volume. The Young's modulus (compressive modulus at $5 \%-10 \%$ strain) of the hydrogels was obtained in a compressive test with the deformation rate of $6 \mathrm{~mm} / \mathrm{min}$ at room temperature.

\subsection{Swelling Ratio Measurement}

The swelling ratio of hydrogels was assessed by weighting the mass of fully hydrated and dried hydrogel. The swollen cylindrical-shaped samples as described were fist weighted as $W_{\mathrm{s}}$. Then, the samples were rinsed with DI water and dried in oven for 1 day and weighted as $W_{\mathrm{d}}$. The swelling ratio of the samples was calculated by the equation as below:

$$
\text { Swelling ratio }(\%)=\left(W_{\mathrm{s}}-W_{\mathrm{d}}\right) / W_{\mathrm{d}} \times 100 \%
$$

All data recorded were averaged from three repeated experiments.

\subsection{Fourier Transformed Infrared (FTIR) Spectra Analysis of PTMAEMA, PA and $P T M A E M A-P A$ Hydrogels}

The formation of ionic bonds and hydrogen bond between quaternary ammonium pendants and PA was confirmed by FT/IR spectra (FT/IR-410, Jasco, Tokyo, Japan). For sample preparation, after submerging pTMAEMA dried gels into PA solution concentration of $1 \mathrm{M}$, pTMAEMA-PA-1 hydrogels were washed for three times with DI water to remove free and loosely bound PA in the hydrogels. The samples were then dried in the oven at $80^{\circ} \mathrm{C}$ for 1 day. Then, the samples were carefully grinded into fine powder and vacuumed for $2 \mathrm{~h}$ before the experiment. pTMAEMA hydrogels and PA were also prepared individually and measured as control samples. 


\subsection{Bacterial Attachment Test}

Escherichia coli (E. coli) (ATCC®25922 ${ }^{\mathrm{TM}}$ ) were used in the experiments. After overnight culture in the incubator at $37^{\circ} \mathrm{C}$. The bacteria were collected by centrifugation at $3000 \mathrm{rpm}$ for $5 \mathrm{~min}$. Cell pellets were then washed with sterile PBS for three times. The bacteria solution was diluted to the optical density at $600 \mathrm{~nm}$ (OD600) of 0.15 using PBS, corresponding to a concentration of $\sim 1.2 \times 10^{8}$ cells/mL. pTMAEMA-anion were sterilized under UV light at $254 \mathrm{~nm}$ for $30 \mathrm{~min}$ and rinsed with sterile PBS (pH 7.4) three times before immersing into $5 \mathrm{~mL}$ of bacterial solutions at $37^{\circ} \mathrm{C}$ in 6 well-plates for $3 \mathrm{~h}$ at $180 \mathrm{rpm}$. The hydrogels were subsequently washed with PBS (pH 7.4) at $100 \mathrm{rpm}$ for three times to discard unattached bacteria. The hydrogels were then treated with LIVE/DEAD BacLight at its working concentration for $15 \mathrm{~min}$ at room temperature in dark room. Fluorescent images were captured from a fluorescent microscope (Nikon Eclipse Ts2-FL, Tokyo, Japan) at $20 \times$ magnification with excited wavelength at 488 and $561 \mathrm{~nm}$ and acquired emitted wavelength at green (510-540 nm) and red (620-650 nm), respectively. Quantitative data of bacterial adhesion were estimated by using ImageJ software and interpreted as the average of triplicates.

\subsection{Antibacterial Activity}

A modified Kirby-Bauer disk diffusion method was applied to study the antibacterial activity of the hydrogels. Staphylococcus epidermidis (S. epidermidis) (ATCC $\left(12228^{\mathrm{TM}}\right.$ ) and Escherichia coli (E. coli) (ATCC®25922 ${ }^{\mathrm{TM}}$ ) were used as Gram-positive and Gram-negative bacteria models in the test. pTMAEMA-PA hydrogels at different loading concentration of $0.1,0.25,0.5$ and $1 \mathrm{M}$ were molded into a round shape ( $7 \mathrm{~mm}$ in diameter, $\sim 2 \mathrm{~mm}$ in thickness) and washed three times for 5 min with DI water. The gels were further sterile under UV light at $254 \mathrm{~nm}$ for $30 \mathrm{~min}$. Overnight-cultured bacteria were diluted to $\mathrm{OD} 600=0.1\left(\sim 10^{8} \mathrm{CFU} / \mathrm{mL}\right)$. Afterward, $10 \mu \mathrm{L}$ of diluted gram-negative and gram-positive bacterial solutions were then plated on LB agar and TSB agar, respectively. Next, the hydrogels were then gently pressed onto cultured agar. The agar plates were then placed in an incubating oven at $37^{\circ} \mathrm{C}$ and left for $10 \mathrm{~h}$ to assess the annular radius for each of the hydrogel. The annular radius was measured by using a vernier caliper with an error of $0.1 \mathrm{~mm}$ for quantitative data.

\section{Results and Discussion}

\subsection{The Effect of Loading Concentration of PA on Mechanical Properties of PTMAEMA}

The negatively-charged PA anion has been reported to form an ionic complex with positively charge amide [45], and has been known as a crosslinking agent in the synthesis of conductive polymers [46,47]. Herein, we demonstrated the effect of PA concentration on the mechanical properties of polyelectrolyte hydrogel. The pTMAEMA hydrogels were dried and then immersed into PA solutions with different concentrations $(0.1,0.25,0.5$ and $1 \mathrm{M})$. As shown in Figure $1 \mathrm{a}$, the mechanical properties of pTMAEMA hydrogels enhanced with PA concentration. The fracture stress and strain of as-prepared pTMAEMA was $24.5 \pm 5 \mathrm{kPa}$ and $29.9 \% \pm 4 \%$, respectively, which are much lower than pTMAEMA-PA-1 (fracture stress at $1101.1 \pm 14 \mathrm{kPa}$ and fracture strain at $84.6 \% \pm 6 \%$ ). The Young's modulus of pTMAEMA-PA-0.1 $(66 \pm 3 \mathrm{kPa})$ was 4.2 times higher than that of as-prepared pTMAEMA $(15.9 \pm 3.7 \mathrm{kPa})$. In addition, the increase of the PA concentration did not affect the Young's modulus (compressive modulus at 5\%-10\% strain offset point) of pTMAEMA hydrogels (Figure 1b). However, at near fracture point, the maximum compressive modulus of pTMAEMA-PA-1 $(9.8 \pm 0.47 \mathrm{MPa})$ was approximately 16.9 times higher than that of pTMAEMA-PA-0.1 $(0.58 \pm 0.07 \mathrm{MPa})$ (Figure 1c). We hypothesized that the changes in modulus at low and high compression reflect two mechanisms of pTMAEMA conformation within the hydrogel. As a multivalent anion, PA induces inter-chain interaction for pTMAEMA via ion-bridging effect [42]. Due to the strong electrostatic interaction of multivalent counterion, the polyelectrolyte gel becomes more compact. Additional anions further infuse into the polymer network to form intra-chain bridges and lead to more chain contraction [48]. As a result, the presence of PA enhances crosslinking density within the hydrophilic network. 


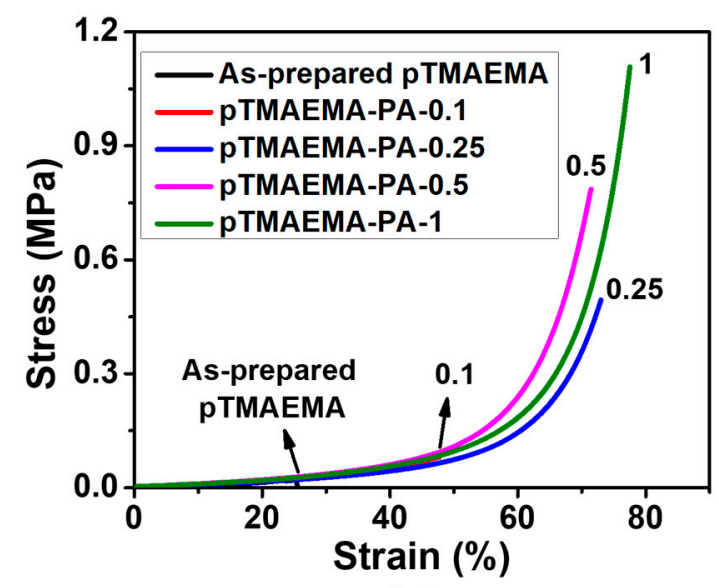

(a)

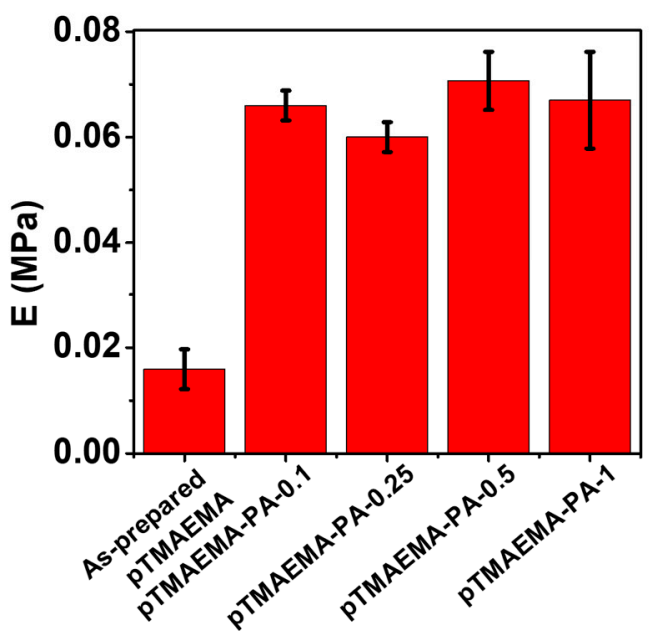

(b)

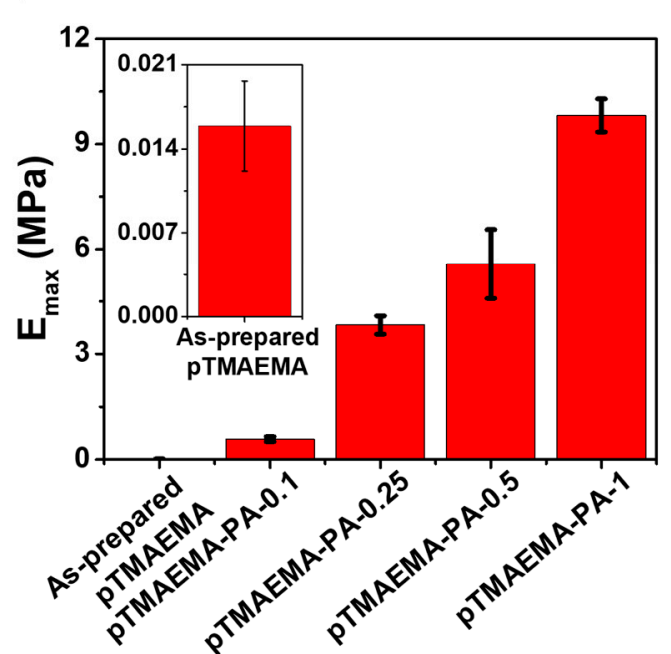

(c)

Figure 1. Concentration-dependent properties of poly((trimethylamino)ethyl methacrylate chloride)phytic acid hydrogel (pTMAEMA-PA): (a) Compressive stress-strain curves of pTMAEMA-PA, (b) Young's modulus $(E)$ and (c) maximum compressive modulus (5\% strain before fracture) $\left(E_{\max }\right)$.

The viscoelastic behavior of pTMAEMA-PA was explored in the rheological study. For all pTMAEMA-PA samples, the storage modulus $G^{\prime}$ was greater than the loss modulus $G^{\prime \prime}$ and $\tan \delta<1$, demonstrating a gel-like property of pTMAEMA-PA (Figure 2a,b). Furthermore, the increase in $G^{\prime}$ according with the PA concentration is due to a higher crosslinking density as well as a higher order of ion bridges distributing within pTMAEMA-PA [49]. Additionally, the tan $\delta$ is closer to 0 when the concentration of PA was $1 \mathrm{M}$, indicating the distinguish elasticity of pTMAEMA-PA- 1 as the ideal elastic material obtains $\tan \delta=0$. Overall, the result confirmed the importance of ionic interaction in the enhanced elasticity of the hydrogel, which is in agreement with the previous report [50].

\subsection{The Fatigue-Resistant Properties and Self-Recovery of pTMAEMA-PA}

The fatigue resistant properties of pTMAEMA-PA-1 were further evaluated by the cyclic compressive test. A loading-unloading cycle of the hydrogel was illustrated in Figure 3a. The areas of hysteresis loops in one loading-unloading cycle represent the energy dissipated per unit gel volume. An increase in the hysteresis area appeared as the strain increased from $60 \%$ to $70 \%$ as shown in Figure $3 \mathrm{~b}$. The results reflected the energy dissipation capability of physically crosslinked hydrogels under deformation [11]. Furthermore, the highly overlapping hysteresis loops in the 1st, 5th and 10th cycle indicate excellent fatigue-resistant ability of pTMAEMA-PA-1. Hysteresis energies remain 
relatively stable after 10 successive loading-unloading cycles (Figure 3c and Figure S1 in Supplementary Materials). Under repetitive stresses, the physical bonds repeatedly disassembled and reformed, leading to the energy dissipation within the hydrogel network, while protecting covalent bonds from permanent breakage. The results from the cyclic compressive test further confirmed the elasticity of pTMAEMA-PA-1, as demonstrated in the rheological study.

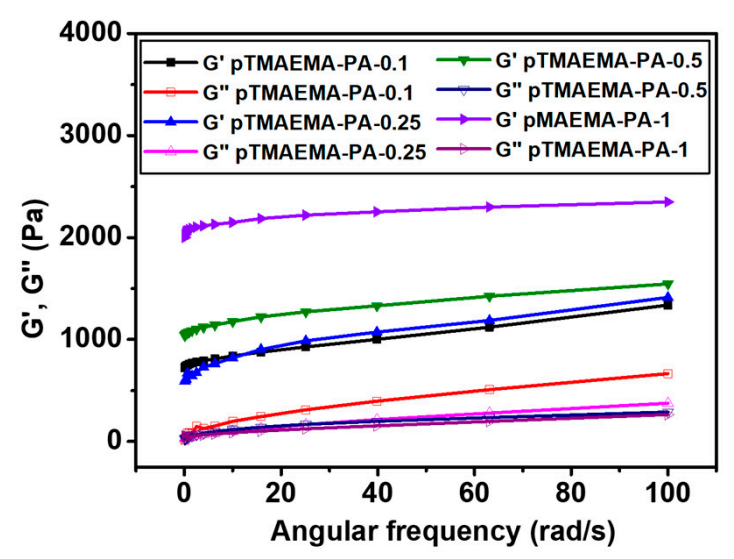

(a)

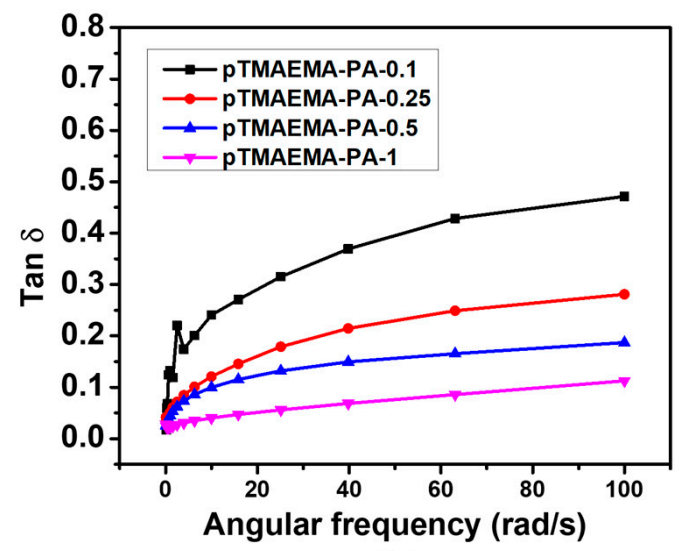

(b)

Figure 2. Dynamic mechanical behaviors of the pTMAEMA-PA hydrogels at a different loading concentration of phytic acid (PA): (a) angular frequency dependence of the storage modulus $G^{\prime}$, loss modulus $G^{\prime \prime}$, and (b) loss factor $\tan \delta$.
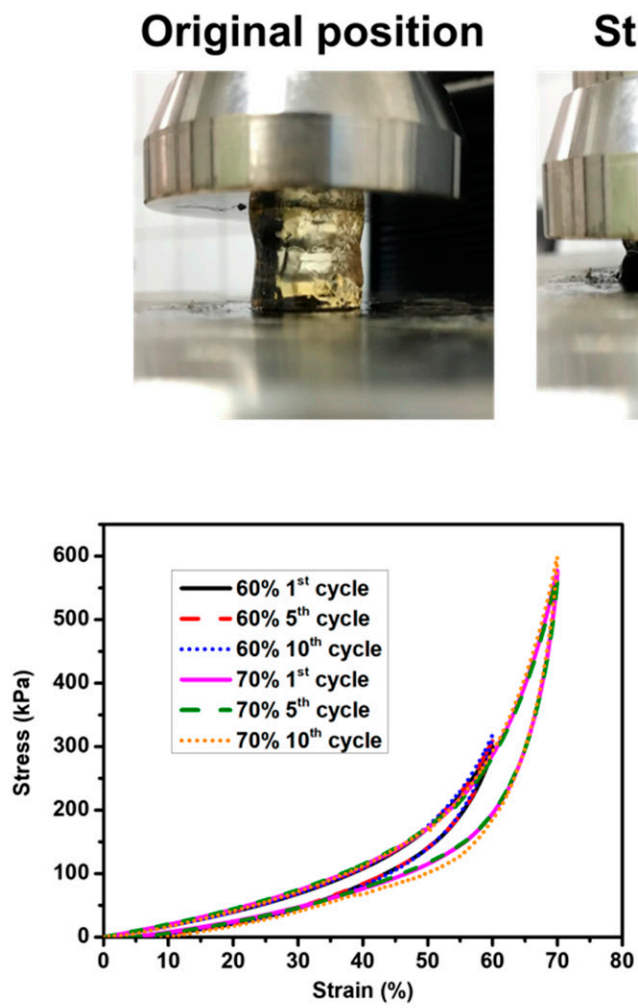

(b)

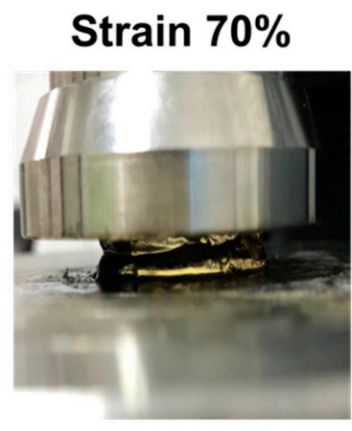

\section{Unloading}

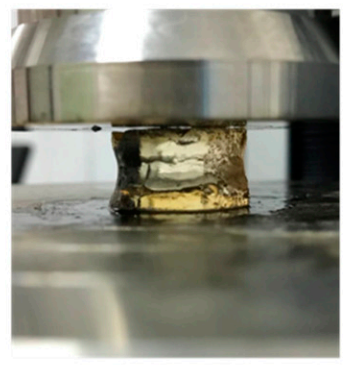

(a)

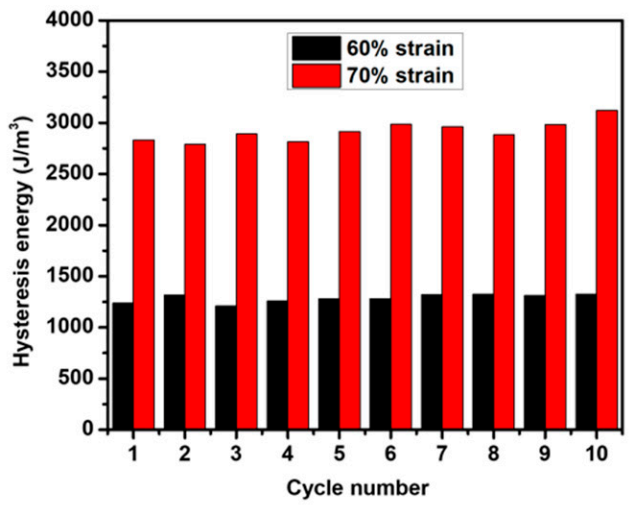

(c)

Figure 3. Fatigue-resistant properties of pTMAEMA-PA-1: (a) Demonstration of one loading-unloading cycle of the hydrogel in 1 cycle at the deformation of $70 \%$ compressive strain, (b) compressive hysteresis curves of PTMAEMA-PA- 1 at $60 \%$ and $70 \%$ compressive strain after 1 st, 5 th and 10 th cycle at deformation rate of $6 \mathrm{~mm} / \mathrm{min}$, and (c) hysteresis energy after 10 successive loading-unloading compression. 


\subsection{Counterion Exchange in $P T M A E M A-P A$}

The stability of ionic complex within pTMAEMA-PA hydrogel can be affected by ionic strength of the $\mathrm{NaCl}$ solution [11]. The increase in the ionic strength of saline solution led to the reduction of the Young's modulus of pTMAEMA-PA-1, from $53.3 \pm 3$ to $25.9 \pm 5 \mathrm{kPa}$ after changing the solution of pure water to $1 \mathrm{M} \mathrm{NaCl}$, respectively (Figure 4). Furthermore, $\mathrm{NaCl}$ concentration influenced the swelling behavior of pTMAEMA-PA-1. Under low ionic strength condition $(<0.15 \mathrm{M} \mathrm{NaCl})$, pTMAEMA-PA-1 deswelled, while re-swelling was observed under a high ionic strength condition, from 0.15 to $1 \mathrm{M} \mathrm{NaCl}$ (Figure 4).

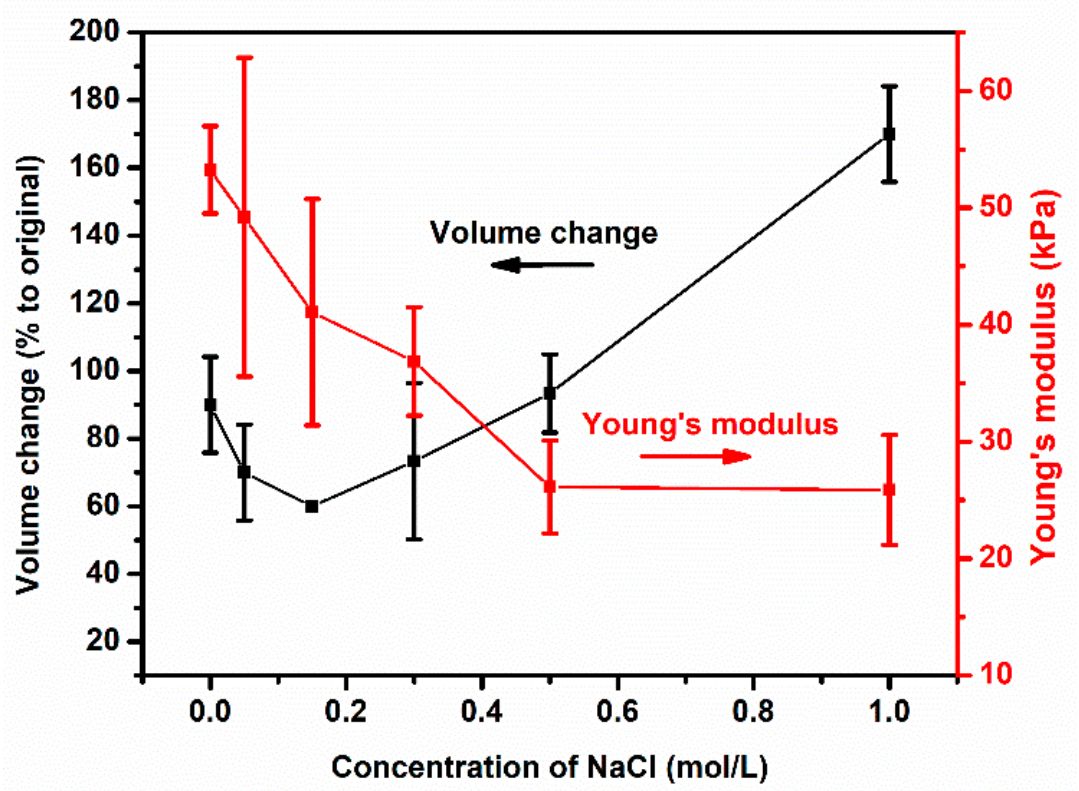

Figure 4. Effect of $\mathrm{NaCl}$ concentration on the volume change and Young's modulus ( $5 \%-10 \%$ strain) of pTMAEMA-PA-1.

The ionic interaction between multivalent ions and polyelectrolyte is governed by two interactions: ion bridges and charge-image charge interaction [42]. The attraction of two polyelectrolytes has been widely reported due to the ion-bridging effect at a low concentration of multivalent counterions, leading to the de-solvation of polyelectrolytes [42]. However, at a high concentration of multivalent ions, the counterions can form strongly correlated liquid layer with polyelectrolyte. This further promotes surface polarization under the liquid layer and the counterions become image charges with opposite charged signs [51]. The repulsive force between incoming counterions and absorbed counterions created correlation holes, which promotes further counterion condensation within polyelectrolytes. The phenomenon was called "correlation attraction" [52]. Eventually, the repulsive forces between multivalent counterions are dominated by the correlation attraction, leading to the re-solvation and re-swelling of polyelectrolyte due to the charge inversion effect [51,52]. It is also worth mentioning that the coexistence between neutral complexes (or ion bridges) and condensation phases via correlation attraction can be achieved under some certain conditions [52]. Assuming that $1 \mathrm{M}$ concentration of PA is high enough for ion bridges and correlation attraction occurs concurrently within pTMAEMA hydrogel. The changes in volume and Young's modulus in pTMAEMA-PA-1 under ion exchange effect can be understood through the theory of reentrant condensation as demonstrated in Scheme 2 [52]: In DI water, no significant change in volume and Young's modulus of pTMAEMA-PA-1 was observed due to the strong correlation attraction and ion bridges within pTMAEMA-PA. In a low ionic strength solution (pure water to $0.15 \mathrm{M} \mathrm{NaCl}$ ), monovalent $\mathrm{Cl}^{-}$can displace the absorbed PA molecules near the solid/liquid interface, resulting in the de-swelling. As a result, the hydrogel shrank due to the removal of condensed counterions. Further increasing $\mathrm{NaCl}$ concentration led to the disassembly of ion bridges 
within the hydrogel. Eventually, pTMAEMA-PA-1 rehydrated and re-swelled, leading to complete charge screening and the marked increase in the volume of pTMAEMA-PA-1.

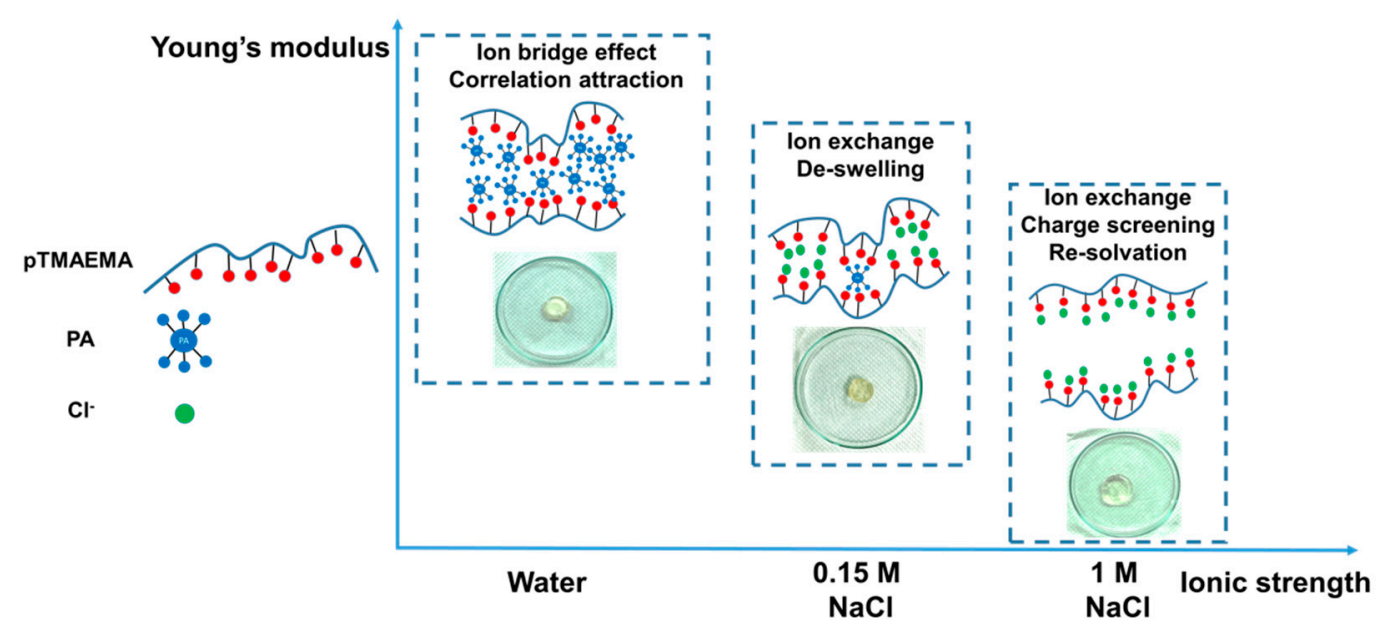

Scheme 2. Effect of $\mathrm{NaCl}$ concentration on the volume change and Young's modulus (5\%-10\% strain) of pTMAEMA-PA-1.

It is worthwhile to acknowledge that the Young's modulus represents the resistance of the material against elastic deformation (non-permanent deformation) when a stress is applied on a material. The reduction in the stiffness of PTMAEMA-PA hydrogels from the stability test confirmed the reversibility of the ionic interaction between PA and quaternary ammonium pendants. Furthermore, it is likely that two coexisting states contribute to the enhancement of mechanical properties of pTMAEMA-PA-1. After rinsing pTMAEMA-PA-1 hydrogels with DI water, the fracture stress of pTMAEMA-PA-1 was still maintained approximately at $1 \mathrm{MPa}$, indicating strong ionic interaction between pTMAEMA and PA (Figure S2 in Supplementary Materials).

\subsection{Counterion Effects on the Swelling Ratio and Mechanical Properties of Polyelectrolyte Hydrogels}

The effect of the ion-pairing strength on the mechanical properties of pTMAEMA hydrogels has been demonstrated above. However, other factors, such as ion size, ion valency and ion specificity, also showed contribution in changing swelling and mechanical properties of polyelectrolyte in simulations and experiments $[37,42,53,54]$. Herein, we conducted a comparative study to elaborate the possible contributing factors that enhance the mechanical properties of pTMAEMA. The hydrogels were dried and then immersed in a series of counterion solutions with different ion valences $\left(\mathrm{Cl}^{-}, \mathrm{SO}_{4}{ }^{2-}, \mathrm{Citrate}^{3-}\right.$, $\mathrm{PP}^{6-}$ and $\mathrm{PA}$ ), and all solutions were kept at the same concentration.

We first compared the swelling ratio of the pTMAEMA hydrogels after introducing different counterions (Figure 5a,b). pTMAEMA hydrogels in DI water obtained high swelling ratio of $\sim 8000 \%$. In addition, the swelling ratio of hydrogels decreased proportionally with the increase in ion valences of counterions, following the order of $\mathrm{Cl}^{-}>\mathrm{SO}_{4}{ }^{2-}>$ citrate $^{3-}>\mathrm{PP}^{6-}>\mathrm{PA}$, which is in agreement with our previous study [27]. Additionally, the driving force at the beginning of the swelling process is based on osmotic pressure difference between the dried hydrogel and the solution [55]. In DI water, pTMAEMA hydrogels exhibit intrinsic electrostatic repulsion between neighbouring polymer chains and the excluded volume effects of the solvated chain side groups, leading to extended conformation of polyelectrolyte and the high swelling ratio of the hydrogel [40]. With the addition of counterions, the charge screening effect occurs, leading to the reduction of charge repulsion effect and the polyelectrolytes collapse [40]. Interestingly, pTMAEMA-PA obtained significantly lower swelling ratio than that of pTMAEMA-PP ${ }^{6-}$ regardless of their similarity in term of ion valency and chemical structure. The results suggest that certain factors can participate in PTMAEMA-anion systems beyond the ion valency. 


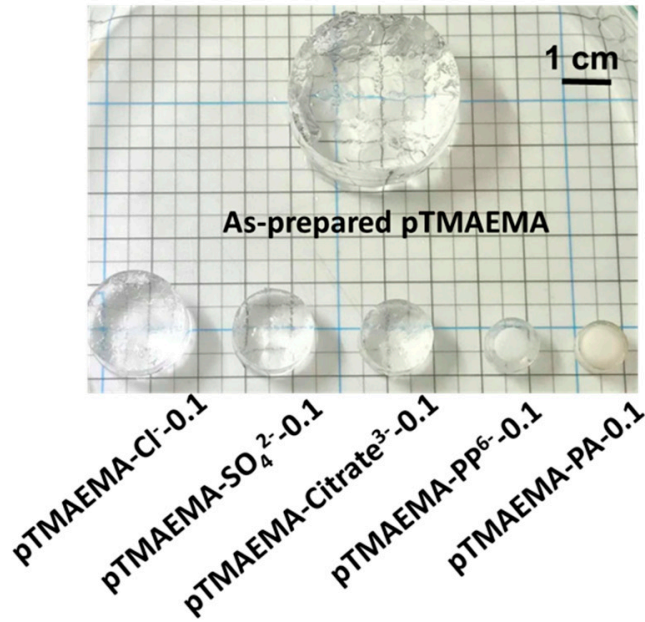

(a)

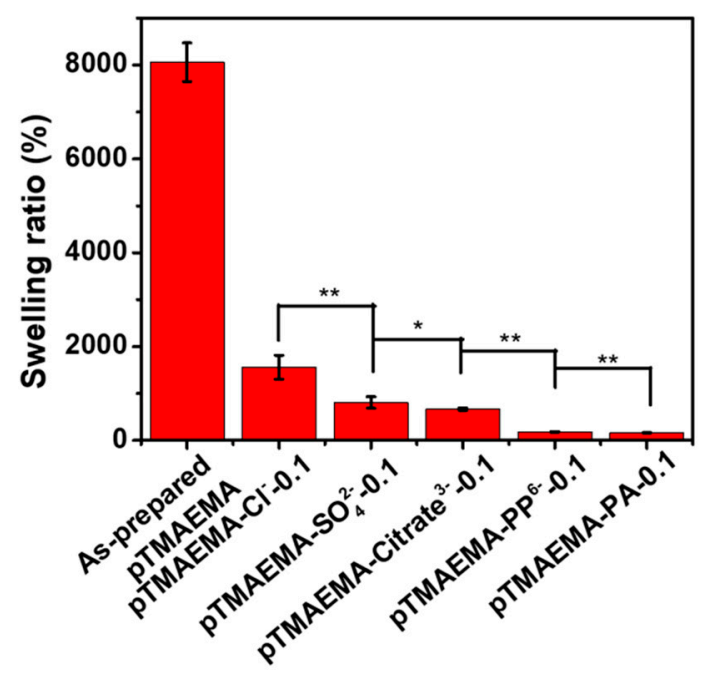

(b)

Figure 5. Appearance (a) and the swelling ratio (b) of pTMAEMA hydrogels in different electrolyte solutions at concentration of $0.1 \mathrm{M}$ after 1 day of submerging in room temperature. ${ }^{*}$ means $P<0.05$ and ${ }^{* *}$ means $P<0.01$.

Therefore, pTMAEMA hydrogels were prepared by immerging pTMAEMA hydrogels in 1M electrolyte solutions to enhance the polymer collapse within the hydrogel networks. As shown in Figures 1 and $6(\mathrm{a}, \mathrm{b})$, as-prepared pTMAEMA hydrogels exhibited low fracture stress, strain and low Young's modulus. The possible reasons behind this mechanical weakness are the low internal friction and the ineffective stress dissipation within polyelectrolyte hydrogel [5,11]. In addition, the inhomogeneous distribution of polyelectrolyte chain length between crosslinking points during the synthesis of the conventional single-network hydrogel also causes uneven force distribution within the hydrogel network [5]. As a result, the short polymer chains under low compression are likely to be damaged first, eventually leading to the complete failure of the hydrophilic network under compression. In contrast, with the addition of counterions, pTMAEMA chains collapses, resulting in an increase in the density of polymer chains in accordance with the decrease in the swelling ratio [54]. This promotes the internal friction between polymer chains, thereby, enhancing energy dissipation in the hydrogels. Comparing between pTMAEMA-anion systems (Figure $6 \mathrm{c}$ ), the fracture stress $\sigma_{\mathrm{f}}$ displayed an order as follow: $\mathrm{SO}_{4}{ }^{2-}<\mathrm{Cl}^{-}<$citrate $^{3-}<\mathrm{PP}^{6-}<\mathrm{PA}$. The compressive toughness Tc recorded from each compressive test further confirmed the order (Figure $6 \mathrm{c}$ ). The fracture stress of pTMAEMA-PA was 13 and 45 times higher than that of PTMAEMA-PP ${ }^{6-}$ and as-prepared pTMAEMA, respectively. In term of Young's modulus, pTMAEMA-PP ${ }^{6-}$ and pTMAEMA-PA exhibit higher stiffness $(50.0 \pm 7.6$ and $67.0 \pm 9.2 \mathrm{kPa}$, respectively) compared with other pTMAEMA-anion complexes.

The differences in mechanical properties of the pTMAEMA-anion systems can be explained as followed:

(1) The fracture stress of pTMAEMA is influenced by ion valency. The mechanical strength of these polyelectrolyte-anion complexes was inversely proportional to the swelling ratio in the case of $\mathrm{Cl}^{-}$, Citrate ${ }^{3-}, \mathrm{PP}^{6-}$ and PA. With the increase in ion valency, the turbidity can be observed in pTMAEMA-PP ${ }^{6-}$ and PTMAEMA-PA occurs likely due to the de-solvation of pTMAEMA by strong ionic coupling of $\mathrm{PP}^{6-}$ and $\mathrm{PA}$ with quaternary ammonium pendants $[42,56]$. The results further indicate the multivalent ion effect on the polyelectrolyte in the formation of inter- and intra- ion bridges.

(2) pTMAEMA- $\mathrm{Cl}^{-}$showed a higher swelling ratio than that of $\mathrm{pTMAEMA}^{-\mathrm{SO}_{4}}{ }^{2-}$, but displayed significantly higher fracture strength. The weak mechanical strength of $\mathrm{pTMAEMA-SO}_{4}{ }^{2-}$ can be understood by the weak ionic coupling between $\mathrm{SO}_{4}{ }^{2-}$ and quaternary ammonium pendants. Following the order of Hofmeister series, the kosmotropic $\mathrm{SO}_{4}{ }^{2-}$ is strongly hydrated, whereas chaotropic $\mathrm{Cl}^{-}$is less hydrated [42,57]. It has been revealed that strongly hydrated species do not easily shed their innermost 
hydration shell, and weakly interact with charged pendants via competition of water molecules [57]. On the contrary, chaotropes exhibit direct ion-pairing with polyelectrolyte, resulting in the "hydrophobic collapse" [41].

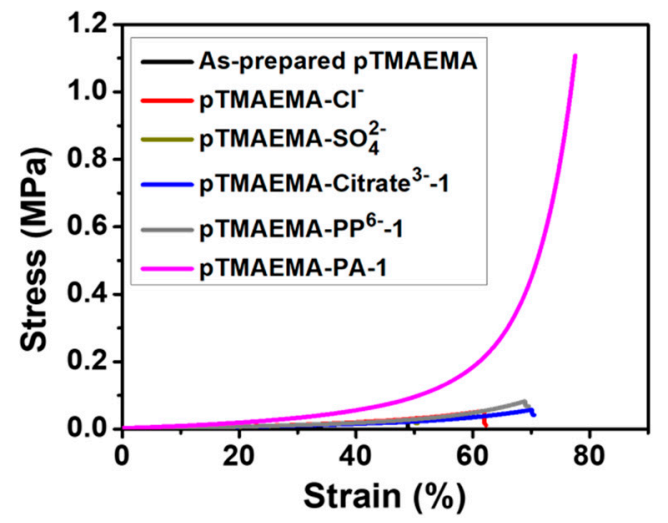

(a)

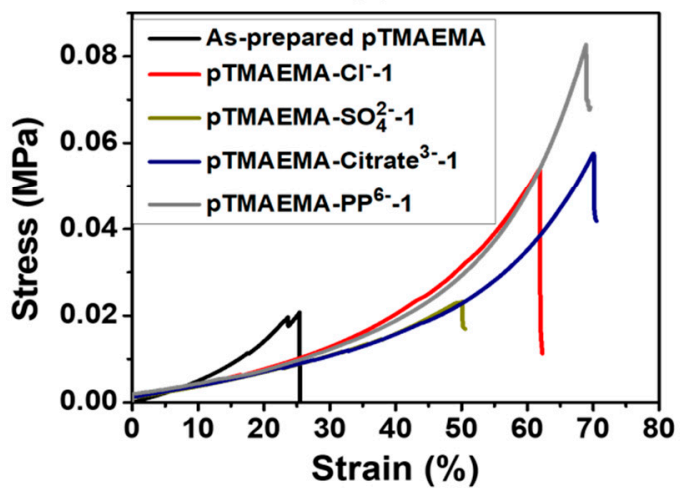

(b)

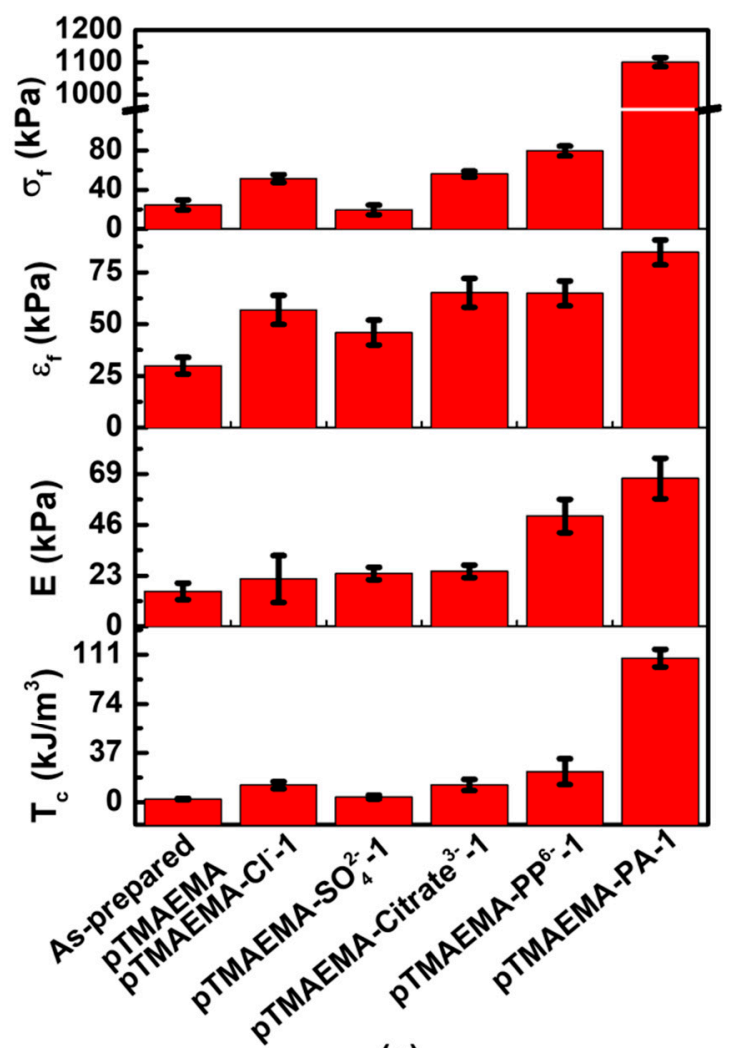

(c)

Figure 6. Compressive stress-strain curves of pTMAEMA-anion $(\mathbf{a}, \mathbf{b})$ and their mechanical properties (c): Fracture stress $\left(\sigma_{\mathrm{f}}\right)$, fracture strain $\left(\epsilon_{\mathrm{f}}\right)$, Young's modulus $(E)$ and compressive toughness $\left(T_{\mathrm{c}}\right)$ of pTMAEMA after immersing in different electrolyte solution at a concentration of $1 \mathrm{M}$ at room temperature after 1 day.

\subsection{FTIR Analysis}

Through the compressive mechanical test, one remaining question is why pTMAEMA-PA exhibited

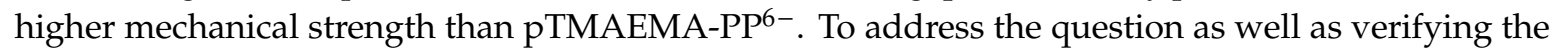
ionic interaction of PA and quaternary ammonium, FTIR spectra measurement was applied. Figure 7a displays the characteristic bands of pTMAEMA center at wavelength number of 3019,2919 and $953 \mathrm{~cm}^{-1}$, corresponding to the asymmetric stretching mode of $\mathrm{CH}_{3}-\mathrm{N}^{+}$, antisymmetric stretching mode of $\mathrm{CH}_{2}$, and stretching mode of $\mathrm{N}^{+}-\left(\mathrm{CH}_{3}\right)_{3}$, respectively [41]. In pTMAEMA-PA spectra, significant red shift was observed (3019 to $2957 \mathrm{~cm}^{-1}$ ) (Figure 7a). The shift in the peak position indicates ionic interaction between anions and pTMAEMA chains due to the sensitivity of the $\mathrm{CH}_{2}$ stretching modes [41]. The redshift observed in our study may suggest the distinct ionic interaction of kosmotropic $\mathrm{HPO}_{4}{ }^{2-}$ anions (anionic groups of PA) on polyelectrolyte chains. It is worth mentioning that the electrostatic interaction of kosmotropes is based on the indirect specific competition for water molecules between counterions and quaternary ammonium moieties of pTMAEMA [42,58]. Therefore, the interaction of kosmostropic anion may promote conformational order in polymer sidechains. In addition, the characteristic absorption peak of $\mathrm{P}-\mathrm{O}-\mathrm{C}$ at $1064 \mathrm{~cm}^{-1}$ appears in pTMAEMA-PA spectra, indicating the success of docking PA on pTMAEMA polymer chains as reported in literature [59]. In Figure 7b, the change in the peak position of $\mathrm{OH}$ bands $\left(3445\right.$ to $3401 \mathrm{~cm}^{-1}$ ) between as-prepared pTMAEMA and 
pTMAEMA-PA confirmed the formation of hydrogen-bonding within pTMAEMA-PA hydrogels [34]. Furthermore, no peak shift in $\mathrm{OH}$ band was observed in the spectra of pTMAEMA-PP ${ }^{6-}$. From the results, we proposed hydrogen bonding formation between hydroxyl groups of PA (hydrogen bond donor) and carbonyl groups on pTMAEMA side chains (hydrogen bond acceptor) [42], which further strengthens the ionic complexation within pTMAEMA-PA hydrogels.

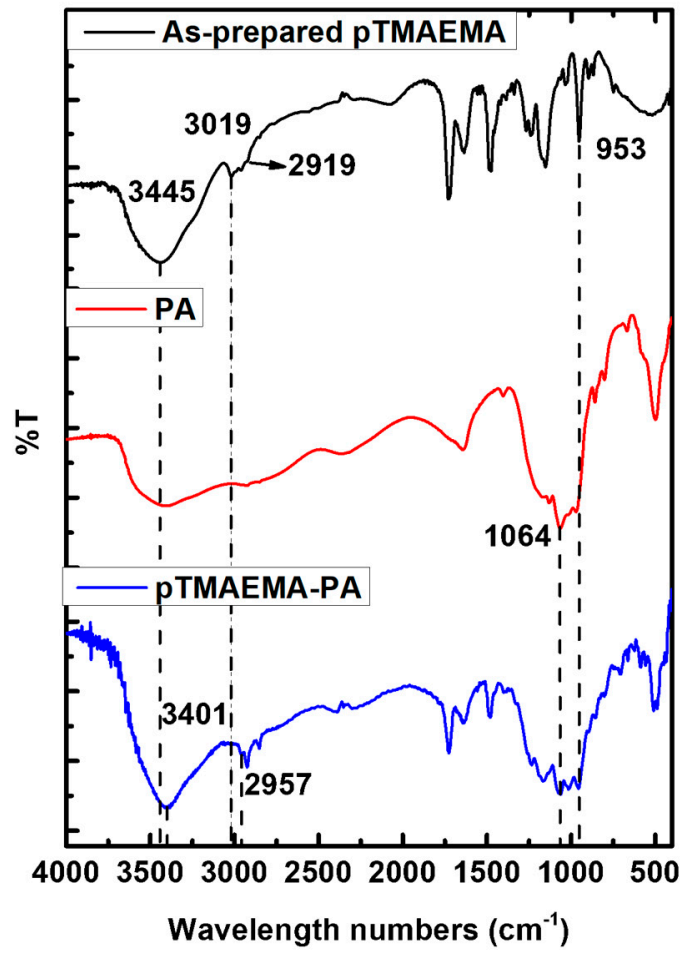

(a)

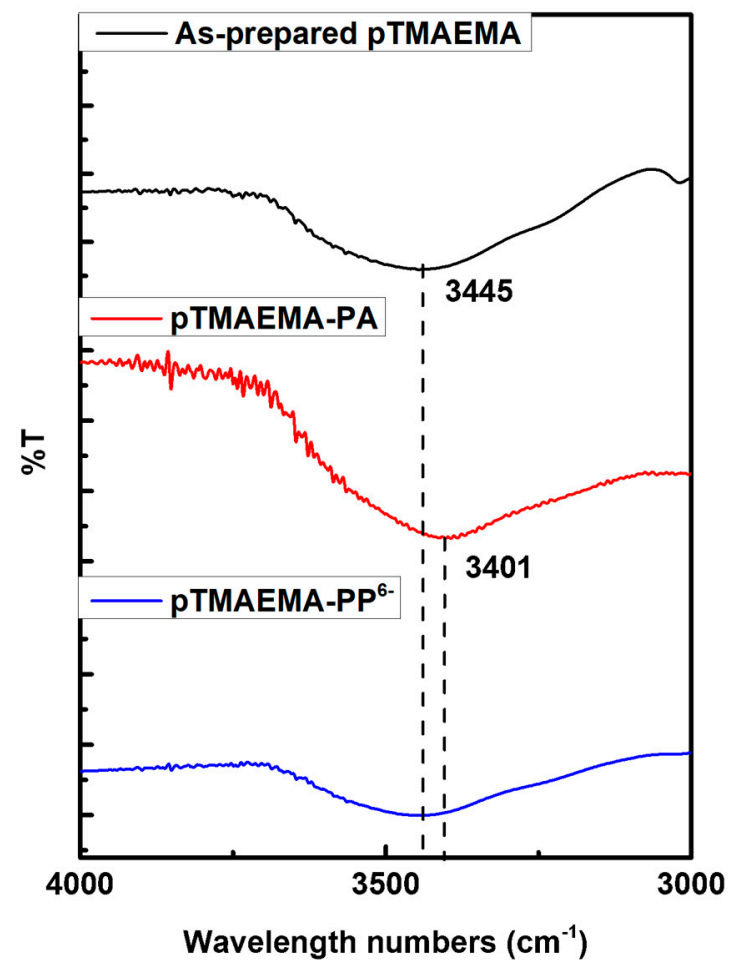

(b)

Figure 7. FTIR spectra analysis: (a) Comparison of FTIR spectra between as-prepared pTMAEMA, PA and pTMAEMA-PA. (b) Comparison of FTIR spectra between as-prepared pTMAEMA, pTMAEMA-PA and PTMAEMA-PP6- at the region from 3000 to $4000 \mathrm{~cm}^{-1}$.

Overall, the proposed mechanisms behind the enhancement in mechanical properties of pTMAEMA hydrogels using PA were summarized in Scheme 1.

\subsection{Bacterial Attachment Test of pTMAEMA-Counterions}

Quaternary ammonium groups have shown their effective antibacterial capability via contact-killing mechanism [27]. However, the accumulation of dead bacterial debris attached on the surface of pTMAEMA is able to condition the surface of the hydrogels, leading to the biofilm formation [23]. Herein, bacterial attachment test was performed to investigate the interfacial properties of PTMAEMA-anion systems. As shown in Figure 8a, the reduction of bacterial attachment was significant on pTMAEMA-PP ${ }^{6-}$ and PTMAEMA-PA. Quantitative data in Figure $8 \mathrm{~b}$ show that the levels of the dead bacterial accumulation on pTMAEMA- $\mathrm{Cl}^{-}$, PTMAEMA- $\mathrm{SO}_{4}{ }^{2-}$ and pTMAEMA-citrate ${ }^{3-}$ were reduced by $70 \%, 67 \%$ and $72 \%$, respectively, in comparison with that on as-prepared pTMAEMA. No significant difference was found in the numbers of live bacteria on these hydrogels. However, the numbers of live bacteria on pTMAEMA-PP ${ }^{-}$and PTMAEMA-PA were only $9 \%$ and $1 \%$ in comparison with that of as-prepared pTMAEMA. As a result, the small number of bacterial attachment observed on pTMAEMA-PP ${ }^{6-}$ may be contributed by two factors: (1) $\mathrm{PP}^{6-}$ anions condition on pTMAEMA surface, leading to the generation of net negative charge and induce repulsive force to bacterial cells [27]; (2) osmotic pressure difference

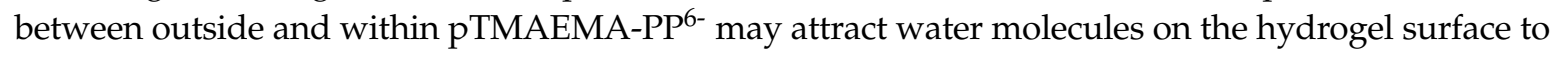
form water layer that prevents biofouling and bacterial growth on hydrogels. 


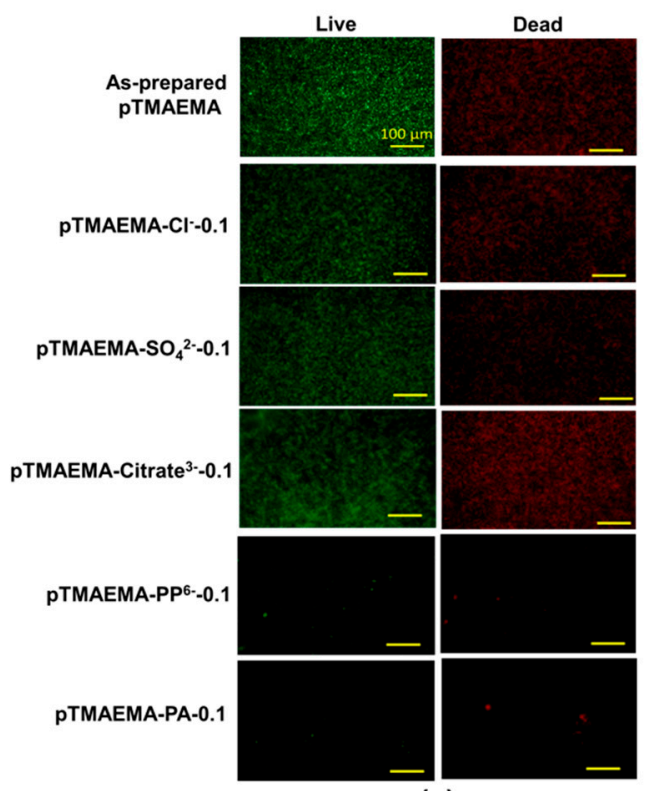

(a)

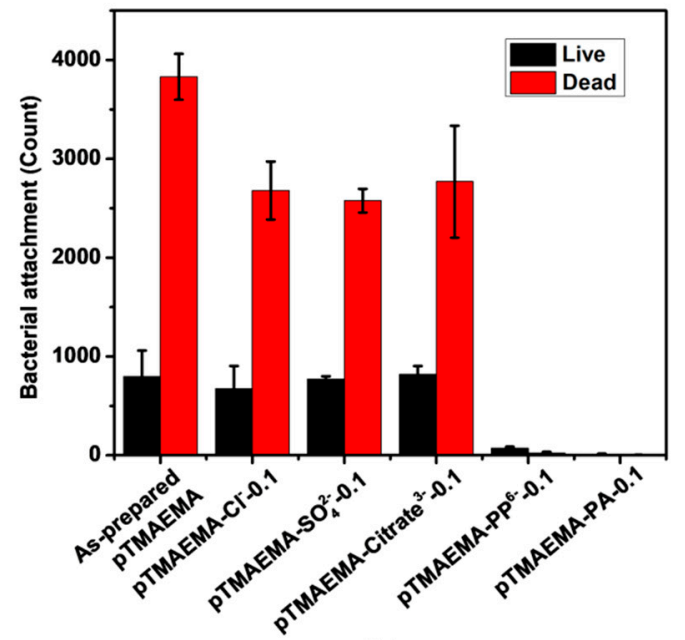

(b)

Figure 8. Bacterial fouling assessment. (a) Fluorescent images of bacteria attachment on pTMAEMAanion-0.1. The bacteria used was E. coli. The color in green represents live bacteria, whereas that in red represents dead bacteria. Scale bar was $100 \mu \mathrm{m}$. (b) Quantification of E. coli attachment on different pTMAEMA hydrogel systems.

\subsection{Antibacterial Capability of pTMAEMA-PA}

The antibacterial capability of counterions was evaluated in agar diffusion test. As illustrated in Figure 9a, only pTMAEMA-PA showed an inhibition zone to suppress the growth of E. coli. The results confirmed the antibacterial activity of PA. In addition, no inhibition zone was shown in agar diffusion test for pTMAEMA- $\mathrm{PP}^{6-}$ even at $1 \mathrm{M}$ loading concentration. Furthermore, higher loading concentration of PA led to increase in the annular radius in both gram-negative E. coli and gram-positive S. epidermidis (Figure $9 b, c$ ). The results suggest that the antimicrobial capability of pTMAEMA-PA is proportional to the loading concentration, which was verified by the PA releasing profile in Figure S3 (in Supplementary Materials). To confirm that the antibacterial activity of PA was not entirely based on the effect of protons in acidic solution, pTMAEMA after immersing in $\mathrm{NaCl}$ solution (at $0.1,0.25,0.5$ and $1 \mathrm{~mol} / \mathrm{L}$ of concentration, $\mathrm{pH}$ adjustment to 2 with $\mathrm{HCl}$ ) was used in as control samples. As shown in Figure $9 \mathrm{~d}$, no inhibition zone was observed in the agar diffusion test, indicating no effect of protons on bacterial growth in disc diffusion test.

Antibacterial capability of pTMAEMA-PA hydrogels can be described based on its chelating effect. Under neutral $\mathrm{pH}$ of bacterial solution, active phosphate groups of PA form chelating complex with divalent cations metal ions $\left(\mathrm{Ca}^{2+}, \mathrm{Mg}^{2+}\right)$. The lack of these metal ions leads to the disruption of the membrane of bacteria [60]. Moreover, charged ions such as protons and other ions in solution can easily get into bacterial cells and cause further internal damage to bacterial organelles and DNA [61]. The chelating effect of PA may also cause damages to bacteria via protein dysfunction [62].

It is expected that PA, as a natural chelating agent, can obtain less cytotoxicity than other agents such as ethylenediamine tetraacetic acid (EDTA). The result in Figure S4 (in Supplementary Materials) further confirm a good biocompatibility of as-prepared pTMAEMA and pTMAEMA-PA-0.1 to NIH/3T3 fibroblasts after co-culturing with 4-day-prepared extraction media from the hydrogels. Some reports also mentioned the effect of PA in enhanced cell activity, cell growth and proliferation at certain doses of PA, which is in agreement with the high cell viability level of NIH/3T3 fibroblasts when exposing with the 1-day-prepared extraction medium of pTMAEMA-PA-0.1 [33,59]. In addition, the safety in PA has been demonstrated in mouse model in several studies [63-65]. Moreover, PA has been acknowledged 
by the U.S. Food and Drug Administration as a food supplement in the Generally Recognized as Safe Notification (GRAS) category [66], which highlighted the beneficial effect of PA. Quaternary ammonium pedants under ion exchange and the change in temperature may disassemble weak ionic bonds formed with anions, hence, maintaining the sustainable release of antibacterial agents from the hydrogels. Nevertheless, the loading concentration of PA can be adjusted to prevent cytotoxicity of pTMAEMA-PA hydrogels, while holding good mechanical properties and antibacterial capability.

E. Coli

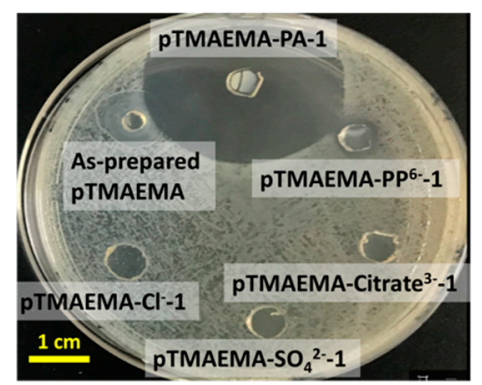

(a)

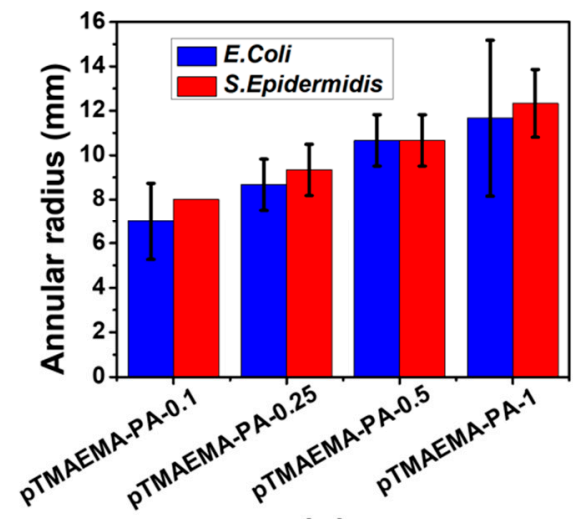

(c)

\section{S. epidermidis}

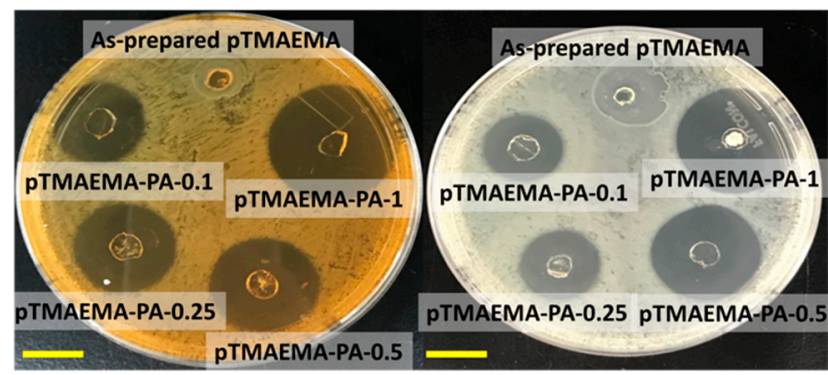

(b)

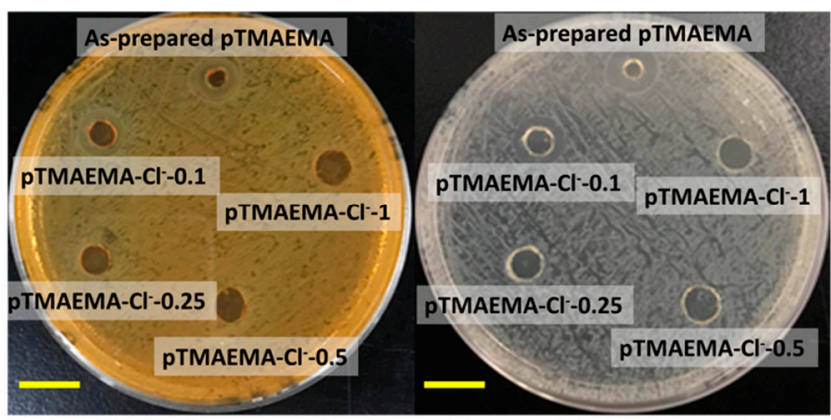

(d)

Figure 9. Antibacterial activity of pTMAEMA-PA. (a) Antibacterial activity of pTMAEMA-PA-1 in compared with other pTMAEMA-anion hydrogels on E. coli. Loading concentration of electrolyte solution was 1 M. (b,c) Concentration-dependent properties of pTMAEMA-PA hydrogels on S. epidermidis and E. coli. (d) Control study of antibacterial activity of PA (pTMAEMA- $\mathrm{Cl}^{-}$prepared with $0.1,0.25,0.5$ and $1 \mathrm{M} \mathrm{NaCl}$ solution with adjusted to $\mathrm{pH} 2$ ).

\section{Conclusions}

In summary, mechanical properties of pTMAEMA hydrogels can be improved by docking multivalent natural counterions. The distinct mechanical properties of different pTMAEMA-anion complexes can be explained by several factors, including ionic strength, multivalent ion effect, ion specificity and hydrogen bonding. Remarkably, pTMAEMA-PA hydrogels obtained superior fracture stress that was 13 and 45 times higher than that of PTMAEMA-PP ${ }^{6-}$ and as-prepared pTMAEMA gels. The evaluation of counterion exchange effect with pTMAEMA-PA-1 revealed that the combination of ion bridges and correlation attraction within the hydrogel contribute to the high mechanical properties of the hydrogels. Furthermore, pTMAEMA-PA-1 hydrogels displayed excellent elasticity with fatigue-resistant property, which was demonstrated in rheological and compressive loading-unloading test. Moreover, from the bacterial adhesion test and the agar diffusion test, pTMAEMA-PA hydrogels showed excellent antifouling and bactericidal properties. Overall, the ionotropic complexation between polyelectrolyte and PA offers great potential for the engineering both tough and antimicrobial materials, as well as other biomedical applications in the future. 
Supplementary Materials: The following are available online at http://www.mdpi.com/2073-4360/11/10/1721/s1, Figure S1: 10 successive loading-unloading cycles of the hydrogel at the deformation of $60 \%$ and $70 \%$ compressive strain. The compressive test was set at a deformation rate of $6 \mathrm{~mm} / \mathrm{min}$ at room temperature; Figure S2: Compressive stress-strain curves of as-prepared pTMAEMA and as-prepare pTMAEMA-PA after rinsing with DI water, PBS $1 \times$ and $\mathrm{NaCl} 4 \mathrm{M}$. The compressive test was set at a deformation rate of $0.5 \mathrm{~mm} / \mathrm{min}$ at room temperature; Figure S3: PA release profile of pTMAEMA-PA incubating at $37^{\circ} \mathrm{C}$ in PBS solution shaking at $100 \mathrm{rpm}$; Figure S4: The cell viability of NIH-3T3 fibroblasts co-incubating with pTMAEMA and pTMAEMA-PA-0.1 in the indirect cytotoxicity test.

Author Contributions: Conceptualization, H.L.B.; Funding acquisition, C.-J.H.; Project administration, C.-J.H.; Supervision, C.-J.H.; Validation, H.L.B.; Writing - original draft, H.L.B.; Writing - review \& editing, C.-J.H.

Funding: The authors wish to acknowledge the Ministry of Science and Technology, Taiwan (MOST 108-2628-E-008 -006 -MY3; 108-2221-E-008 -062 -MY3) for financial support of this project.

Conflicts of Interest: The authors declare no conflict of interest.

\section{References}

1. Liu, Y.; He, W.; Zhang, Z.; Lee, B. Recent developments in tough hydrogels for biomedical applications. Gels 2018, 4, 46. [CrossRef] [PubMed]

2. Liu, M.; Zeng, X.; Ma, C.; Yi, H.; Ali, Z.; Mou, X.; Li, S.; Deng, Y.; He, N. Injectable hydrogels for cartilage and bone tissue engineering. Bone res. 2017, 5, 17014. [CrossRef] [PubMed]

3. Yuk, H.; Zhang, T.; Parada, G.A.; Liu, X.; Zhao, X. Skin-inspired hydrogel-elastomer hybrids with robust interfaces and functional microstructures. Nat. Commun. 2016, 7, 12028. [CrossRef] [PubMed]

4. Liu, Z.; Calvert, P. Multilayer hydrogels as muscle-like actuators. Adv. Mater. 2000, 12, 288-291. [CrossRef]

5. Gong, J.P. Why are double network hydrogels so tough? Soft Matter 2010, 6, 2583. [CrossRef]

6. Haraguchi, K.; Takehisa, T. Nanocomposite hydrogels: a unique organic-inorganic network structure with extraordinary mechanical, optical, and swelling/de-swelling properties. Adv. Mater. 2002, 14, 1120-1124. [CrossRef]

7. Chen, Q.; Zhu, L.; Chen, H.; Yan, H.; Huang, L.; Yang, J.; Zheng, J. A Novel Design Strategy for Fully Physically Linked Double Network Hydrogels with Tough, Fatigue Resistant, and Self-Healing Properties. Adv. Funct. Mater. 2015, 25, 1598-1607. [CrossRef]

8. Zheng, S.Y.; Ding, H.; Qian, J.; Yin, J.; Wu, Z.L.; Song, Y.; Zheng, Q. Metal-Coordination Complexes Mediated Physical Hydrogels with High Toughness, Stick-Slip Tearing Behavior, and Good Processability. Macromolecules 2016, 49, 9637-9646. [CrossRef]

9. Tang, L.; Liu, W.; Liu, G. High-strength hydrogels with integrated functions of H-bonding and thermoresponsive surface-mediated reverse transfection and cell detachment. Adv. Mater. 2010, 22, 2652-2656. [CrossRef]

10. Mihajlovic, M.; Staropoli, M.; Appavou, M.-S.; Wyss, H.M.; Pyckhout-Hintzen, W.; Sijbesma, R.P. Tough supramolecular hydrogel based on strong hydrophobic interactions in a multiblock segmented copolymer. Macromolecules 2017, 50, 3333-3346. [CrossRef]

11. Sun, T.L.; Kurokawa, T.; Kuroda, S.; Ihsan, A.B.; Akasaki, T.; Sato, K.; Haque, M.A.; Nakajima, T.; Gong, J.P. Physical hydrogels composed of polyampholytes demonstrate high toughness and viscoelasticity. Nat. Mater. 2013, 12, 932-937. [CrossRef] [PubMed]

12. Allen, H.K.; Donato, J.; Wang, H.H.; Cloud-Hansen, K.A.; Davies, J.; Handelsman, J. Call of the wild: antibiotic resistance genes in natural environments. Nat. Rev. Microbiol. 2010, 8, 251. [CrossRef] [PubMed]

13. Varaprasad, K.; Mohan, Y.M.; Ravindra, S.; Reddy, N.N.; Vimala, K.; Monika, K.; Sreedhar, B.; Raju, K.M. Hydrogel-silver nanoparticle composites: a new generation of antimicrobials. J. Appl. Polym. Sci. 2010, 115, 1199-1207. [CrossRef]

14. Thoniyot, P.; Tan, M.J.; Karim, A.A.; Young, D.J.; Loh, X.J. Nanoparticle-hydrogel composites: Concept, design, and applications of these promising, multi-functional materials. Adv. Sci. 2015, 2, 1400010. [CrossRef]

15. Ikeda, T.; Hirayama, H.; Yamaguchi, H.; Tazuke, S.; Watanabe, M. Polycationic biocides with pendant active groups: molecular weight dependence of antibacterial activity. Antimicrob. Agents Chemother. 1986, 30, 132-136. [CrossRef]

16. Li, P.; Poon, Y.F.; Li, W.; Zhu, H.-Y.; Yeap, S.H.; Cao, Y.; Qi, X.; Zhou, C.; Lamrani, M.; Beuerman, R.W. A polycationic antimicrobial and biocompatible hydrogel with microbe membrane suctioning ability. Nat. Mater. 2011, 10, 149. [CrossRef] 
17. Eren, T.; Som, A.; Rennie, J.R.; Nelson, C.F.; Urgina, Y.; Nüsslein, K.; Coughlin, E.B.; Tew, G.N. Antibacterial and hemolytic activities of quaternary pyridinium functionalized polynorbornenes. Macromol. Chem. Phys. 2008, 209, 516-524. [CrossRef]

18. Wang, J.; Chen, Y.P.; Yao, K.; Wilbon, P.A.; Zhang, W.; Ren, L.; Zhou, J.; Nagarkatti, M.; Wang, C.; Chu, F. Robust antimicrobial compounds and polymers derived from natural resin acids. Chem. Commun. 2012, 48, 916-918. [CrossRef]

19. Gan, D.; Xu, T.; Xing, W.; Ge, X.; Fang, L.; Wang, K.; Ren, F.; Lu, X. Mussel-Inspired Contact-Active Antibacterial Hydrogel with High Cell Affinity, Toughness, and Recoverability. Adv. Funct. Mater. 2019, 29, 1805964. [CrossRef]

20. Cheng, G.; Xue, H.; Zhang, Z.; Chen, S.; Jiang, S. A switchable biocompatible polymer surface with self-sterilizing and nonfouling capabilities. Angew. Chem. Int. Ed. 2008, 47, 8831-8834. [CrossRef]

21. Huang, K.-T.; Fang, Y.-L.; Hsieh, P.-S.; Li, C.-C.; Dai, N.-T.; Huang, C.-J. Zwitterionic nanocomposite hydrogels as effective wound dressings. J. Mater. Chem. B 2016, 4, 4206-4215. [CrossRef]

22. Zheng, H.-T.; Bui, H.L.; Chakroborty, S.; Wang, Y.; Huang, C.-J. PEGylated metal-phenolic networks for antimicrobial and antifouling properties. Langmuir 2019, 35, 8829-8839. [CrossRef] [PubMed]

23. Wei, T.; Tang, Z.; Yu, Q.; Chen, H. Smart antibacterial surfaces with switchable bacteria-killing and bacteria-releasing capabilities. ACS Appl. Mater. Interfaces 2017, 9, 37511-37523. [CrossRef]

24. Yu, Q.; Shivapooja, P.; Johnson, L.M.; Tizazu, G.; Leggett, G.J.; López, G.P. Nanopatterned polymer brushes as switchable bioactive interfaces. Nanoscale 2013, 5, 3632-3637. [CrossRef] [PubMed]

25. Yan, S.; Shi, H.; Song, L.; Wang, X.; Liu, L.; Luan, S.; Yang, Y.; Yin, J. Nonleaching bacteria-responsive antibacterial surface based on a unique hierarchical architecture. ACS Appl. Mater. Interfaces 2016, 8, 24471-24481. [CrossRef] [PubMed]

26. Wei, T.; Zhan, W.; Yu, Q.; Chen, H. Smart Biointerface with Photoswitched Functions between Bactericidal Activity and Bacteria-Releasing Ability. ACS Appl. Mater. Interfaces 2017, 9, 25767-25774. [CrossRef]

27. Huang, C.-J.; Chen, Y.-S.; Chang, Y. Counterion-activated nanoactuator: reversibly switchable killing/releasing bacteria on polycation brushes. ACS Appl. Mater. Interfaces 2015, 7, 2415-2423. [CrossRef]

28. Cowan, M.M. Plant products as antimicrobial agents. Clin. Microbiol. Rev. 1999, 12, 564-582. [CrossRef]

29. Seeram, N.P.; Adams, L.S.; Henning, S.M.; Niu, Y.; Zhang, Y.; Nair, M.G.; Heber, D. In vitro antiproliferative, apoptotic and antioxidant activities of punicalagin, ellagic acid and a total pomegranate tannin extract are enhanced in combination with other polyphenols as found in pomegranate juice. J. Nutr. Biochem. 2005, 16, 360-367. [CrossRef]

30. Gryglewski, R.J.; Korbut, R.; Robak, J.; Święs, J. On the mechanism of antithrombotic action of flavonoids. Biochem. Pharmacol. 1987, 36, 317-322. [CrossRef]

31. Souza, S.; Aquino, L.; Milach, A.C., Jr.; Bandeira, M.; Nobre, M.; Viana, G. Antiinflammatory and antiulcer properties of tannins from Myracrodruon urundeuva Allemão (Anacardiaceae) in rodents. Phytother. Res. 2007, 21, 220-225. [CrossRef] [PubMed]

32. Li, M.; Wang, H.; Hu, J.; Hu, J.; Zhang, S.; Yang, Z.; Li, Y.; Cheng, Y. Smart Hydrogels with Antibacterial Properties Built from All Natural Building Blocks. Chem. Mater. 2019, 31, 7678-7685. [CrossRef]

33. Meininger, S.; Blum, C.; Schamel, M.; Barralet, J.E.; Ignatius, A.; Gbureck, U. Phytic acid as alternative setting retarder enhanced biological performance of dicalcium phosphate cement in vitro. Sci. Rep. 2017, 7, 558. [CrossRef] [PubMed]

34. Chen, K.; Zhang, S.; Li, A.; Tang, X.; Li, L.; Guo, L. Bioinspired Interfacial Chelating-like Reinforcement Strategy toward Mechanically Enhanced Lamellar Materials. ACS nano 2018, 12, 4269-4279. [CrossRef]

35. Barahuie, F.; Dorniani, D.; Saifullah, B.; Gothai, S.; Hussein, M.Z.; Pandurangan, A.K.; Arulselvan, P.; Norhaizan, M.E. Sustained release of anticancer agent phytic acid from its chitosan-coated magnetic nanoparticles for drug-delivery system. Int. J. Nanomedicine 2017, 12, 2361. [CrossRef]

36. Patil, P.; Chavanke, D.; Wagh, M. A review on ionotropic gelation method: novel approach for controlled gastroretentive gelispheres. Int. J. Pharm. Pharm. Sci. 2012, 4, 27-32.

37. Yang, C.H.; Wang, M.X.; Haider, H.; Yang, J.H.; Sun, J.-Y.; Chen, Y.M.; Zhou, J.; Suo, Z. Strengthening alginate/polyacrylamide hydrogels using various multivalent cations. ACS Appl. Mater. Interfaces 2013, 5, 10418-10422. [CrossRef]

38. Azzaroni, O.; Zheng, Z.; Yang, Z.; Huck, W.T. Polyelectrolyte brushes as efficient ultrathin platforms for site-selective copper electroless deposition. Langmuir 2006, 22, 6730-6733. [CrossRef] 
39. Moya, S.; Azzaroni, O.; Farhan, T.; Osborne, V.L.; Huck, W.T. Locking and unlocking of polyelectrolyte brushes: toward the fabrication of chemically controlled nanoactuators. Angew. Chem. Int. Ed. Engl. 2005, 44, 4578-4581. [CrossRef]

40. Azzaroni, O.; Brown, A.A.; Huck, W.T. Tunable wettability by clicking counterions into polyelectrolyte brushes. Adv. Mater. 2007, 19, 151-154. [CrossRef]

41. Azzaroni, O.; Moya, S.; Farhan, T.; Brown, A.A.; Huck, W.T.S. Switching the Properties of Polyelectrolyte Brushes via "Hydrophobic Collapse". Macromolecules 2005, 38, 10192-10199. [CrossRef]

42. Liu, G. Tuning the Properties of Charged Polymers at the Solid/Liquid Interface with Ions. Langmuir 2018, 35, 3232-3247. [CrossRef] [PubMed]

43. Debye, P. The theory of electrolytes I. The lowering of the freezing point and related occurrences. Phys. Z 1923, 24, 185-206.

44. Kunz, W. Specific ion effects in colloidal and biological systems. Curr. Opin. Colloid Interface Sci. 2010, 15, 34-39. [CrossRef]

45. Zhang, T.; Yan, H.; Shen, L.; Fang, Z.; Zhang, X.; Wang, J.; Zhang, B. Chitosan/phytic acid polyelectrolyte complex: a green and renewable intumescent flame retardant system for ethylene-vinyl acetate copolymer. Ind. Eng. Chem. Res. 2014, 53, 19199-19207. [CrossRef]

46. Chen, P.-Y.; Courchesne, N.-M.D.; Hyder, M.N.; Qi, J.; Belcher, A.M.; Hammond, P.T. Carbon nanotubepolyaniline core-shell nanostructured hydrogel for electrochemical energy storage. RSC Adv. 2015, 5, 37970-37977. [CrossRef]

47. Pan, L.; Yu, G.; Zhai, D.; Lee, H.R.; Zhao, W.; Liu, N.; Wang, H.; Tee, B.C.-K.; Shi, Y.; Cui, Y. Hierarchical nanostructured conducting polymer hydrogel with high electrochemical activity. Proc. Natl. Acad. Sci. USA 2012, 109, 9287-9292. [CrossRef]

48. Pu, Q.; Ng, S.; Mok, V.; Chen, S.B. Ion bridging effects on the electroviscosity of flexible polyelectrolytes. J. Phys. Chem. B 2004, 108, 14124-14129. [CrossRef]

49. Song, D.; Kang, B.; Zhao, Z.; Song, S. Stretchable self-healing hydrogels capable of heavy metal ion scavenging. RSC Adv. 2019, 9, 19039-19047. [CrossRef]

50. Wang, C.; Deitrick, K.; Seo, J.; Cheng, Z.; Zacharia, N.S.; Weiss, R.; Vogt, B.D. Manipulating the mechanical response of hydrophobically cross-linked hydrogels with ionic associations. Macromolecules 2019, 52, 6055-6067. [CrossRef]

51. Wang, T.; Long, Y.; Liu, L.; Wang, X.; Craig, V.S.; Zhang, G.; Liu, G. Cation-specific conformational behavior of polyelectrolyte brushes: from aqueous to nonaqueous solvent. Langmuir 2014, 30, 12850-12859. [CrossRef] [PubMed]

52. Grosberg, A.Y.; Nguyen, T.; Shklovskii, B. Colloquium: the physics of charge inversion in chemical and biological systems. Rev. Mod. Phys. 2002, 74, 329. [CrossRef]

53. Sing, C.E.; Zwanikken, J.W.; Olvera de la Cruz, M. Effect of ion-ion correlations on polyelectrolyte gel collapse and reentrant swelling. Macromolecules 2013, 46, 5053-5065. [CrossRef]

54. Henderson, K.J.; Zhou, T.C.; Otim, K.J.; Shull, K.R. Ionically cross-linked triblock copolymer hydrogels with high strength. Macromolecules 2010, 43, 6193-6201. [CrossRef]

55. Horkay, F.; Tasaki, I.; Basser, P.J. Osmotic swelling of polyacrylate hydrogels in physiological salt solutions. Biomacromolecules 2000, 1, 84-90. [CrossRef]

56. de La Cruz, M.O.; Belloni, L.; Delsanti, M.; Dalbiez, J.; Spalla, O.; Drifford, M. Precipitation of highly charged polyelectrolyte solutions in the presence of multivalent salts. J. Chem. Phys. 1995, 103, 5781-5791. [CrossRef]

57. Zhang, Y.; Furyk, S.; Bergbreiter, D.E.; Cremer, P.S. Specific ion effects on the water solubility of macromolecules: PNIPAM and the Hofmeister series. J. Am. Chem. Soc. 2005, 127, 14505-14510. [CrossRef]

58. Nihonyanagi, S.; Yamaguchi, S.; Tahara, T. Counterion effect on interfacial water at charged interfaces and its relevance to the Hofmeister series. J. Am. Chem. Soc. 2014, 136, 6155-6158. [CrossRef]

59. Wang, X.; Wen, K.; Yang, X.; Li, L.; Yu, X. Biocompatibility and anti-calcification of a biological artery immobilized with naturally-occurring phytic acid as the crosslinking agent. J. Mater. Chem. B 2017, 5, 8115-8124. [CrossRef]

60. Kim, N.H.; Rhee, M.S. Phytic Acid and Sodium Chloride Show Marked Synergistic Bactericidal Effects against Nonadapted and Acid-Adapted Escherichia coli O157:H7 Strains. Appl. Environ. Microbiol. 2016, 82, 1040-1049. [CrossRef]

61. Kim, N.H.; Rhee, M.S. Synergistic bactericidal action of phytic acid and sodium chloride against Escherichia coli O157: H7 cells protected by a biofilm. Int. J. Food Microbiol. 2016, 227, 17-21. [CrossRef] [PubMed] 
62. Percival, S.L.; Kite, P.; Eastwood, K.; Murga, R.; Carr, J.; Arduino, M.J.; Donlan, R.M. Tetrasodium EDTA as a novel central venous catheter lock solution against biofilm. Infect. Control Hosp. Epidemiol. 2005, 26, 515-519. [CrossRef] [PubMed]

63. Gaetke, L.M.; McClain, C.J.; Toleman, C.J.; Stuart, M.A. Yogurt protects against growth retardation in weanling rats fed diets high in phytic acid. J. Nutr. Biochem. 2010, 21, 147-152. [CrossRef] [PubMed]

64. Hiasa, Y.; Kitahori, Y.; Morimoto, J.; Konishi, N.; Nakaoka, S.; Nishioka, H. Carcinogenicity study in rats of phytic acid 'Daiichi', a natural food additive. Food Chem. Toxicol. 1992, 30, 117-125. [CrossRef]

65. Szkudelski, T. Phytic acid-induced metabolic changes in the rat. J. Anim. Physiol. Anim. Nutr. 2005, 89, 397-402. [CrossRef] [PubMed]

66. GRAS Notices. Available online: https://www.accessdata.fda.gov/scripts/fdcc/?set=GRASNotices\&id=381 (accessed on 13 October 2019).

(C) 2019 by the authors. Licensee MDPI, Basel, Switzerland. This article is an open access article distributed under the terms and conditions of the Creative Commons Attribution (CC BY) license (http://creativecommons.org/licenses/by/4.0/). 